\title{
Speculation and Hedging in Segmented Markets,
}

\author{
Itay Goldstein \\ Department of Finance, Wharton School, University of Pennsylvania
}

Yan Li

Department of Finance, Fox School of Business, Temple University

\author{
Liyan Yang \\ Department of Finance, Joseph L. Rotman School of Management, \\ University of Toronto
}

\begin{abstract}
We analyze a model in which traders have different trading opportunities and learn information from prices. The difference in trading opportunities implies that different traders may have different trading motives when trading in the same market—some trade for speculation and others for hedging - and thus they may respond to the same information in opposite directions. This implies that adding more informed traders may reduce price informativeness and therefore provides a source for learning complementarities leading to multiple equilibria and price jumps. Our model is relevant to various realistic settings and helps to understand a variety of modern financial markets. (JEL G14, G12, G11, D82)
\end{abstract}

\section{Introduction}

Modern financial markets are populated by different types of traders, who have different trading opportunities. In this paper, we demonstrate that this market segmentation feature has unexpected consequences for market efficiency and other aspects of asset prices. In a nutshell, the difference in trading opportunities implies that different traders have different motives when trading a given asset-some trade for speculation, while others trade for hedging — and this might reduce price efficiency and cause excess volatility.

\footnotetext{
For helpful comments and discussions, we thank Efstathios Avdis, Henry Cao, Vincent Glode, Jeremy Graveline, Jungsuk Han, Tom McCurdy, Maureen O'Hara, Marcus Opp, Günter Strobl, James R. Thompson, Yajun Wang, Masahiro (Masa) Watanabe, and participants at the 2011 China International Conference in Finance (Wuhan, China), the 2011 European Finance Association Conference (Stockholm, Sweden), the 2011 Northern Finance Association Conference (Vancouver, Canada), and the 2012 Financial Intermediation Research Society Conference (Minneapolis, U.S.). We are especially grateful to the editor (David Hirshleifer) and an anonymous referee for constructive comments that have significantly improved the paper. Yang thanks the Social Sciences and Humanities Research Council of Canada for financial support. Send correspondence to Itay Goldstein, Department of Finance, Wharton School, University of Pennsylvania, Philadelphia, PA 19104; telephone: (215)746-0499. E-mail: itayg@wharton.upenn.edu.
}

(C) The Author 2013. Published by Oxford University Press on behalf of The Society for Financial Studies. All rights reserved. For Permissions, please e-mail: journals.permissions@oup.com. doi:10.1093/rfs/hht059 
The market segmentation induced by traders with different trading opportunities is relevant to many real-world examples. We review some of them in Section 3 A leading example is the commodities futures markets. In this market, financial institutions are limited to trade in the futures contracts and use them for speculation purposes, while commodities producers trade the futures contracts mostly for hedging, as they fulfill their speculative activities directly in the production markets. Hence, in the commodity futures market, the different types of traders trade in different directions in response to information-some trade for speculation and others for hedging. This can lead to a reduction in price informativeness and an increase in the futures risk premium.

Other examples involve convertible bonds markets and credit default swaps (CDS) markets. Typically, some institutions, mostly hedge funds, trade in these markets while at the same time they also trade in the underlying bond or equity markets. Other traders, such as retail investors and traditional institutional investors, are limited to trading in the underlying traditional markets due to various frictions reviewed in Section 3.3 Hence, the situation highlighted by our analysis arises, as hedge funds may respond to information in the opposite direction in their trading in the underlying market than the traditional investors, leading to negative implications for market efficiency and an increase in the cost of capital. We discuss additional examples of similar segmentation, such as across international markets (where some investors are affected by home bias and others invest across borders), and with human capital markets.

We build a model to formally analyze the pricing and efficiency implications of the market segmentation featured in these real-world examples. Our model is based on the classic paper of Grossman and Stiglitz 1980) and extends it to consider multiple segmented markets. We have two types of (rational) traders - traders with a relatively small investment opportunity set, $S$-traders (e.g., individuals or mutual funds), and traders with a relatively large investment opportunity set, L-traders (e.g., hedge funds) - and two types of correlated risky assets $-A$ (e.g., stocks, bonds) and $B$ (e.g., convertible bonds, CDS). Markets are segmented, such that $\mathrm{S}$-traders can only trade the A-asset, while L-traders can trade both types of assets 1 All traders observe the prices of both assets. The two risky assets share a common fundamental component, and L-traders may use the commonly traded A-asset to hedge their investments in the B-asset (or vice versa). Before entering the financial market, $\mathrm{S}$-traders can collect private information about the common fundamental at some cost, while L-traders are endowed with private information.

We solve the model in closed form and characterize how the prices of the two assets are determined. We further analyze how the cost of capital and price informativeness of these two assets depend on interesting model parameters, such as the number of L-traders and the profitability of speculative positions in

1 The letters "L" and "S" in "L-traders" and "S-traders" mean large and small investment opportunities, respectively. The letter "A" in the risky "A-asset" means that all traders can trade it. 
the B-asset. The results depend crucially on the trading behavior of L-traders. More specifically, L-traders trade the risky A-asset for two reasons: speculating based on superior information about the A-asset's payoff, and hedging their investment in the B-asset. Depending on the strength of these two motives, our model generates very different results regarding the cost of capital and price informativeness. Of particular interest to us is the case where the hedging motive in the A-asset is strong. In this case, L-traders trade very differently from $S$-traders and tend to reduce the informativeness of the price and increase the cost of capital.

In Section 5.3 we discuss the implications of these results for policy and empirical work. First, considering the futures markets, our model sheds new light on the determinants of the futures risk premium and how it is affected by the financialization of commodities markets. This can guide policy debate regarding the desirability of this trend. Second, there is wide debate concerning the optimal scope of hedge fund activities, and our model speaks to such debate by showing when the trading activities of hedge funds (L-traders in many of our examples) are damaging to market efficiency. Third, our model provides a framework to analyze the effect of trading derivatives, such as CDS markets, on the efficiency of the primary underlying markets.

We further study the incentive of S-traders to collect information regarding the fundamental of the commonly traded A-asset. Most of the existing literature predicts that when more investors are informed, the value of the information is reduced, and investors have less incentive to gather information, resulting in strategic substitution in learning 2 In our model, however, learning complementarities can naturally arise. That is, as more S-traders become informed, information becomes more valuable, and uninformed S-traders have a stronger incentive to collect it, generating strategic complementarity in information acquisition. The intuition is as follows. Suppose that the fundamental of the two assets is strong. If L-traders can better explore the trading opportunities in the B-asset, they will increase their investment in the $\mathrm{B}$-asset and decrease their investment in the A-asset (due to hedging). When the price informativeness of the A-asset is determined mainly by the L-traders' hedging-motivated trading, raising the number of informed S-traders will raise their speculative demand, making the two offsetting forces-from informed S-traders and L-traders-more balanced. This, in turn, will make the price less responsive to changes in information, so that uninformed S-traders have a more difficult time gleaning information from prices. The resulting learning complementarities can generate multiplicity of equilibria and excess volatility in prices.

2 In particular, Grossman and Stiglitz 1980, 394) formulated the following two conjectures about price informativeness and strategic learning: "Conjecture 1: The more individuals who are informed, the more informative is the price system. ... Conjecture 2: The more individuals who are informed, the lower the ratio of the expected utility of the informed to the uninformed." 
We emphasize that the basic premise underlying our results is that markets are segmented in terms of the ability to move capital across markets and trade in different markets due to various frictions, but not so much in terms of price information. In other words, capital is relatively segmented and slow moving (e.g., Duffie 2010), but information is relatively integrated and fast moving, and traders actively use this information (e.g.,Cespa and Foucault 2012). In fact, we show in Appendix B.2 that our results hinge on the ability of traders to observe and understand market prices even in the markets in which they do not trade. We argue in Section 3.3 that this notion of segmentation/integration is very relevant for today's markets given the improvement of information technology on the one hand and the specialization and delegation of investment on the other hand, making it easy for information to flow across markets but putting frictions on the flow of capital.

\subsection{Related literature}

Our paper is broadly related to five strands of theoretical literature. First, our paper contributes to the literature that develops different mechanisms that generate strategic complementarity in information acquisition in financial markets. Froot, Scharfstein, and Stein 1992) show that if traders have short horizons, they may herd on the same type of information and learn what other informed traders also know. Hirshleifer, Subrahmanyam, and Titman 1994) demonstrate the possibility of strategic complementarity in collecting information when some traders receive private information before others. Veldkamp 2006a, 2006 b) relies on fixed costs in information production to generate strategic complementarities and explain large jumps and comovement in asset prices. Garcia and Strob 2011) study how relative wealth concerns affect investors' incentives to acquire information. Barlevy and Veronesi 2000, 2008) and Breon-Drish 2011) generate strategic complementarities with non-normally distributed asset payoff structures. Our paper proposes a different mechanism for strategic complementarities in financial markets-namely that traders, who have related pieces of information but have different investment opportunity sets, may wish to trade an asset in different directions, thereby reducing price informativeness. As we argue in Section 3 our mechanism is relevant to various realistic settings and captures a key feature of modern financial markets.

Second, our paper is related to the literature on derivative markets. In particular, as we show in Section 3.1 our model can be viewed as a setting of the commodity futures market, and our analysis provides a new information channel for commodity hedgers to affect futures prices. By contrast, the literature has largely ignored this channel because most models are conducted in a setup without asymmetric information (see, e.g., Hirshleifen 1988a, 1988b; Gorton, Hayashi, and Rouwenhorst 2013). The only exceptions that we are aware of are Stein 1987) and Sockin and Xiong 2013). Our paper differs from and complements both papers in terms of research questions and mechanisms. Stein 1987) studies how speculation affects price volatility and welfare, and 
in his model, the entry of informed speculators brings into the price the noise in their signals, which lowers price informativeness and can lead to price destabilization and welfare reduction. Sockin and Xiong 2013) develop a model to study an information channel for commodity futures prices to feed back to commodity demand and spot prices, and provide implications for transparency and econometric implementations. In contrast, our model examines information transmission occurring in the futures market, and the negative informativeness effect is caused by behaviors of those traders who are informed of the same information but respond to this information in opposite directions. In addition, our analysis focuses on futures premiums and explores implications for learning.

The applications of our analysis to other derivatives also link our paper to the theoretical and empirical studies on options, CDS, etc. For example, Biais and Hillion 1994) develop a model to show that introducing options can alleviate the market breakdown problem by completing the markets, but can also complicate the information inference problem of market makers by complexifying the strategies of informed insiders. Chakravarty, Gulen, and Mayhew 2004) find evidence that informed traders trade in both stock and option markets and affect price discovery. Recently, Boehmer, Chava, and Tookes 2012 provide evidence that the trading in different derivative markets affects the equity market in different ways. Our paper complements those studies by highlighting a new channel (segmentation) through which the effect of informed trading on efficiency might be negative.

The third line of research related to our paper is the study of multiple assets in (noisy) rational expectations equilibrium settings. Admati 1985) is the first to analyze the properties of noisy rational expectations equilibria for a class of economies with many risky assets. Watanabe 2008) and Biais, Bossaerts, and Spatt 2010) extend Admati's model to an overlapping generation setting to study the effect of asymmetric information and supply shocks on portfolio choice, return volatility, and trading volume. Yuan 2005) introduces borrowing constraints into a two-asset model and shows how trading can cause contagion across two fundamentally independent markets. Van Nieuwerburgh and Veldkamp 2009, 2010) show that the interactions between the multi-asset portfolio problem and the information acquisition problem help to explain the home-bias puzzle and the underdiversification puzzle. All the above-mentioned papers assume that all investors have equal access to the same investment vehicles, unlike the market-segmentation scenarios that are the focus of our paper. We demonstrate in Appendix B.1 that this segmentation is key to our results.

Fourth, a number of papers feature hedging-motivated trading in financial assets. Glosten (1989), Spiegel and Subrahmanyam 1992), Dow and Rahi (2003), Goldstein and Guembel 2008) and Kyle, Ou-Yang, and Wei 2011), among others, study Kyle 1985)-type models with endogenous noise trading generated from risk-averse uninformed hedgers who hedge their endowment 
risk optimally. Similar formulations of hedging motives also appear in Grossman-Stiglitz (1980)-type models - for example, Duffie and Rahi 1995), Lo, Mamaysky, and Wang (2004), Watanabe 2008), Biais, Bossaerts, and Spatt 2010) and Huang and Wang 2010). In all these papers, hedgers' endowments are assumed to be correlated with the performance of some underlying tradable asset, and hence they have an incentive to use the asset to hedge their endowment shocks. The hedging-motivated trading in this literature is mainly a device to prevent fully revealing prices and/or to complete the model (by endogenizing noise trading). In contrast, in our paper, the hedging-motivated trading on the (A-) asset does not come from the passive endowment shocks, but instead comes from the active trading from another related (B-) asset. This creates the inherent link between speculation and hedging, which is at the core of our model. This channel has strong empirical motivation and is particularly suitable for analyzing how different trading opportunities affect asset prices and information acquisition.

Finally, there are previous papers that analyzed different notions of segmentation in information-based models. For example, see Chowhdry and Nanda 1991) and Madhavan (1995). They consider cases with multiple markets, where the information from one market may not be available to traders in the other market. In contrast, our notion of segmentation is that of different trading opportunities for different traders, and we do allow for information flows across markets. As we wrote above, we believe that nowadays, with the improved technology, segmentation does not occur in terms of price information but in terms of the ability to shift capital across markets (due to frictions involving delegation and specialization). Recently, Cespa and Foucaul 2012) use a setting similar to ours (but without L-traders) to study how learning across segmented markets can generate liquidity comovement.

\section{The Model}

\subsection{Environment}

Time is discrete and has three dates $(t=0,1,2)$. At date 1 , a competitive financial market opens, and there are three tradable assets: one riskless asset, and two risky assets, A and B. As in Grossman and Stiglitz 1980), we set the price of the riskless asset to 1 , and let $\tilde{p}_{A}$ and $\tilde{p}_{B}$ denote the prices of the two risky assets, respectively 3 The riskless asset is in zero net supply, and each unit delivers one "dollar" at date 2. The riskless asset can be thought of as risk-free loans, and for simplicity, we have normalized the net interest rate to 04 Assets A and B have a supply of $\bar{x}_{A} \geq 0$ and $\bar{x}_{B} \geq 0$, respectively. At date 2 , the A-asset pays a normally distributed random cash flow $\tilde{v}_{A}$, and the B-asset pays a normally

3 Throughout the paper, a tilde ( $)$ signifies a random variable.

4 Our results are robust to a specification of non-zero net interest rate. 
distributed random cash flow $\tilde{v}_{B}$. As we will specify below, the payoffs of the two risky assets are assumed to be correlated.

There are two classes of rational traders in the economy: L-traders (of mass $\lambda>0$ ) and S-traders (of mass 1). Traders derive their expected utility only from their date- 2 wealth; they have constant-absolute-risk-aversion (CARA) utility functions over wealth $W:-e^{-\gamma W}$, where $\gamma$ is the risk-aversion parameter. The crux of our model is the assumption that different traders have different investment opportunity sets. Specifically, L-traders have a larger investment opportunity set than S-traders: at date 1, L-traders can trade all three assets, while S-traders can trade only the riskless asset and the A-asset5 But, while trading opportunities are different across the two types of traders, they all observe both prices $\tilde{p}_{A}$ and $\tilde{p}_{B}$. This can be justified, given that nowadays investors can easily obtain this kind of price information via the Internet. Hence, our model features segmentation in trading opportunities and not in the observability of prices. We think that this fits the reality of modern financial markets, where capital may be slow to move across markets, but information is not. In Section 3.3 we will provide more general evidence for this feature in relevant real-world markets.

In both the A-asset market and the B-asset market, there are noise traders, who trade for exogenous liquidity reasons. We use $\tilde{n}_{A} \sim \mathcal{N}\left(0, \sigma_{n A}^{2}\right)$ (with $\left.\sigma_{n A}>0\right)$ to denote noise trading in the A-asset market and $\tilde{n}_{B} \sim \mathcal{N}\left(0, \sigma_{n B}^{2}\right)$ (with $\sigma_{n B}>0$ ) to denote noise trading in the B-asset market. For tractability, we assume that $\tilde{n}_{A}$ is independent of $\tilde{n}_{B}$, which is reasonable given that the two markets are segmented. As is usually the case in the literature, noise trading can be generated by liquidity needs or distorted beliefs. Our results do not depend on the size of $\sigma_{n A}$ relative to $\sigma_{n B}$.

\subsection{Asset payoffs and information structure}

At date 0 , rational traders can purchase data that is useful in forecasting the payoffs $\tilde{v}_{A}$ and $\tilde{v}_{B}$ of the risky assets. If they do so, the signal they receive is $\tilde{\theta}$, which can be thought of as the fundamental of the assets. The payoffs of the risky assets are then:

$$
\left\{\begin{array}{l}
\tilde{v}_{A}=\tilde{\theta}+\tilde{\varepsilon}_{A}, \\
\tilde{v}_{B}=\phi \tilde{\theta}+\tilde{\varepsilon}_{B},
\end{array}\right.
$$

where $\tilde{\varepsilon}_{A}$ and $\tilde{\varepsilon}_{B}$ are residual noise terms conditional on the signal $\tilde{\theta}$. We assume that the signal and noise terms are normally distributed: $\tilde{\theta} \sim \mathcal{N}\left(0, \sigma_{\theta}^{2}\right)$, $\tilde{\varepsilon}_{A} \sim \mathcal{N}\left(0, \sigma_{\varepsilon A}^{2}\right)$, and $\tilde{\varepsilon}_{B} \sim \mathcal{N}\left(0, \sigma_{\varepsilon B}^{2}\right)\left(\sigma_{\theta}, \sigma_{\varepsilon A}, \sigma_{\varepsilon B}>0\right) 6$ The two noise terms

5 One can think of the L-traders as being collectively endowed with the total supply $\bar{x}_{B}$ of asset B, while $\mathrm{L}$ - and S-traders together can be thought of as being collectively endowed with the total supply $\bar{x}_{A}$ of asset A. Because of the CARA feature of preferences, their individual endowments have no effect on the solution, and hence there is no need to specify them.

6 For simplicity, we have assumed that the asset payoffs have a zero mean. Our results do not depend on this assumption. 
$\left(\tilde{\varepsilon}_{A}, \tilde{\varepsilon}_{B}\right)$ are independent of the fundamental $\tilde{\theta}$, but are correlated with one another with the coefficient $\rho \in(0,1)$. The parameter $\phi$ is greater than 0 ; it represents the sensitivity of asset B's payoff to the signal (the sensitivity of asset A's payoff is normalized to one).

Let us clarify the payoff structure. Our model is meant to capture a situation in which two correlated assets are traded in segmented markets. Segmentation is represented by the fact that some traders have access to only one of the two markets. As mentioned above, we assume correlation across assets in fundamentals and in noise terms, and lack of correlation between each noise term and the fundamental. This generates the link between speculation and hedging, which is central to the main mechanism in our model. This structure can be justified by thinking of the "fundamentals" of the two risky assets as the result of estimation from data using an ordinary-least-squares regression. Since the payoffs on both assets are correlated, their estimated "fundamentals" as well as residual noise terms will be correlated, while, at the same time, the noise terms will be independent of the estimated fundamentals. Note that, for simplicity, we assume that the fundamentals of the two assets are captured by a single random variable $\tilde{\theta}$, and are thus perfectly correlated. Our results are robust to a more general assumption that they are only imperfectly correlated.

Finally, we assume that L-traders have better access to data than S-traders. Specifically, L-traders can collect data at no cost (and so observe $\tilde{\theta}$ for sure), while S-traders have to spend a cost $\tau>0$ to acquire the data and hence the signal $\tilde{\theta}$. This assumption fits with the L-traders being more hands-on in these markets, which gives them more access to trading opportunities and to data about the underlying fundamentals 7 An S-trader is called informed if he chooses to acquire the signal $\tilde{\theta}$ and uninformed otherwise. Like Grossman and Stiglitz 1980), at date 1 , the asset prices $\tilde{p}_{A}$ and $\tilde{p}_{B}$ will partially reveal the signal $\tilde{\theta}$ through the trading of the informed S-traders and the L-traders. The uninformed $S$-traders can extract information about $\tilde{\theta}$ from observing prices. Of course, informed S-traders and L-traders also observe prices, but this extra price information is redundant in forecasting $\tilde{\theta}$, given that they know $\tilde{\theta}$ perfectly.

\subsection{Timeline}

The timeline of the model is as follows. At date $0, \mathrm{~S}$-traders choose whether or not to acquire the signal $\tilde{\theta}$ at $\operatorname{cost} \tau>0$. L-traders costlessly observe $\tilde{\theta}$. At date 1 , the financial market opens. Informed and uninformed S-traders trade the riskless asset and the A-asset at prices 1 and $\tilde{p}_{A}$, respectively. L-traders trade the riskless asset, the A-asset, and the B-asset at prices $1, \tilde{p}_{A}$, and $\tilde{p}_{B}$,

7 This assumption is not necessary, but it makes the analysis simple by not having to consider both informed and uninformed L-traders. In some cases, such as the commodity markets example in Section 3.1 S-traders could be more informed than L-traders. Our main results should remain unchanged under this alternative specification, because the mechanism emphasized by our analysis is still at work - that is, L- and S-traders can respond to the same information $\tilde{\theta}$ in opposite directions. 
respectively. Noise traders trade $\tilde{n}_{A}$ in the A-asset and $\tilde{n}_{B}$ in the B-asset. At date 2 , payoffs are received and all rational traders consume.

To summarize, $\left(\tilde{\theta}, \tilde{\varepsilon}_{A}, \tilde{\varepsilon}_{B}, \tilde{n}_{A}, \tilde{n}_{B}\right)$ are underlying random variables that characterize the economy. They are all independent of each other, except that $\tilde{\varepsilon}_{A}$ and $\tilde{\varepsilon}_{B}$ are positively correlated with each other with the coefficient $\rho \in(0,1)$. The tuple $\mathcal{E}=\left(\lambda, \gamma, \tau, \bar{x}_{A}, \bar{x}_{B}, \rho, \phi, \sigma_{\theta}, \sigma_{\varepsilon A}, \sigma_{\varepsilon B}, \sigma_{n A}, \sigma_{n B}\right)$ defines an economy.

In Section 4 we provide the analysis of the model described in this section. But, before turning to the analysis, in the next section we discuss the empirical relevance of this model by describing a variety of real-world markets that are captured by our general setup.

\section{Empirical Relevance of the Model}

\subsection{Speculation and hedging in a commodity futures market}

As a leading example, in this subsection, we work out a setup of a commodity futures market that can exactly produce the model structure specified in the previous section 8 In relation to our model setup, assets $A$ and $B$ correspond to a futures contract on the commodity and to the input that is used to produce the commodity, respectively. For concreteness, we can refer to the commodity as crops, and therefore asset $\mathrm{A}$ is the crop futures contract, and asset B can be the land that is used for growing crops. L-traders are the primary crop suppliers, such as crop producers, who trade crop futures to hedge their crops production and also buy land to conduct the production. S-traders are outside speculators such as futures mutual funds or hedge funds, who trade crop futures to speculate but do not trade the land directly. Noise trading $\tilde{n}_{A}$ and $\tilde{n}_{B}$ represent random transient demands in the crop futures market and in the land market, respectively.

The sequence of events is as follows. At date 1, trade happens in the two asset markets - the crop futures market and the land market. Crop producers participate in both asset markets, and speculators trade only crops futures. Their trading decisions together with noise trading generate a futures price $\tilde{p}_{A}$ and a land price $\tilde{p}_{B}$. At date 2 , the crop spot price is determined based on the supply and demand for crops. This spot price $\tilde{p}_{\text {crop }}$ pins down the payoff on the crop futures contract and the land that were traded at date 1 .

In this example, it is clear that both of our key assumptions about the nature of segmentation are satisfied: (i) L-traders (crop producers) purchase land and trade crop futures, while S-traders (futures mutual/hedge funds) trade only crop futures; (ii) All traders are aware of the prices of land and crop futures, because the futures prices are readily available from the Chicago Mercantile Exchange

8 Commodity markets have historically been partly segmented from other financial markets (e.g., Bessembinder 1992). In recent years, financial institutions have greatly increased their investments in commodity futures. For example, the CFTC Staff Report (2008) documents that the value of index-related commodities futures investments grew from \$15 billion during 2003 to over \$200 billion during 2008. 
and land prices are also publicly available at sources such as Land and Property Values (for the United States) and Farmland Values Report (for Canada). Hence, segmentation exists in the type of traders involved in trading in the different markets, but not in price observability. We next demonstrate that our assumed payoff structure in $\$$ naturally comes out of this example.

As mentioned above, the payoffs on the futures contract and the land traded at date 1 are determined by the spot price $\tilde{p}_{\text {crop }}$ of date 2 . As in Hirshleifer 1988 1988b), we assume that the demand for the crop $Q\left(\tilde{p}_{\text {crop }}\right)$ is implicitly derived from the preference of some (unmodeled) consumers and it is represented by a linear demand function:

$$
Q\left(\tilde{p}_{\text {crop }}\right)=\tilde{v}_{A}-\tilde{p}_{\text {crop }} .
$$

Here, $\tilde{v}_{A}$ represents an exogenous shock to consumers' crop demand. In equilibrium, as we will show, $\tilde{v}_{A}$, adjusted by a constant, will pin down the payoff to asset A (the futures contract on crops). To connect to Equation (1), we specify that the demand shock $\tilde{v}_{A}$ is decomposed as: $\tilde{v}_{A}=\tilde{\theta}+\tilde{\varepsilon}_{A}$. Here, $\tilde{\theta}$ is the component of which traders may be informed and $\tilde{\varepsilon}_{A}$ is the one of which they are not informed. For example, $\tilde{\theta}$ can represent factors related to business cycles determining consumers' wealth level, on which there are many detailed macro data available that traders can purchase and analyze. In contrast, $\tilde{\varepsilon}_{A}$ may represent noise affecting consumers' personal taste parameters, which are hard to predict given available data sources.

The land (the B-asset) has a fixed supply of $\bar{x}_{B}>0$. Suppose that each piece of land produces $\phi_{1}>0$ units of crops at date 2 . Therefore, the total supply of crops is $\phi_{1} \bar{x}_{B}$. So, the market-clearing condition of the crop spot market at date 2 is:

$$
\phi_{1} \bar{x}_{B}=Q\left(\tilde{p}_{\text {crop }}\right) \text {, }
$$

that is, the total supply of crops produced by all pieces of land is equal to the total demand for crops from consumers. This equation implies that the crop spot price is:

$$
\tilde{p}_{\text {crop }}=\tilde{v}_{A}-\phi_{1} \bar{x}_{B} .
$$

Hence, we can see that the payoff of the crop futures contract (i.e., the A-asset) is equal to $\tilde{v}_{A}$ adjusted by a constant $-\phi_{1} \bar{x}_{B}$ 可 This is because, at date 1 , the buyer of a crop futures contract promises to buy one unit of crop at date 2 at a prespecified price $\tilde{p}_{A}$, and so from the perspective of date 1 , this contract is an asset that costs $\tilde{p}_{A}$ and generates a payoff equal to the date- 2 crop spot price $\tilde{p}_{\text {crop }}$. Of course, the supply $\bar{x}_{A}$ of the crop futures contract is 0 , since it is a derivative traded among traders themselves.

We now specify the payoff of the B-asset (i.e., the land), which we denote as $\tilde{v}_{B}$ (as in Equation (1)). First, each piece of land will generate a payoff from

9 Our model results will not be affected by adjusting the asset payoffs with a constant. 
the production of crops, which will be equal to the number of crops produced multiplied by the spot price-that is, $\phi_{1} \tilde{p}_{\text {crop }}$. In addition, we say that the land has some residual value, denoted by $\tilde{v}_{\text {landres }}$, coming from crops production in future periods or from other uses (e.g., construction). Hence, the payoff of the $\mathrm{B}$-asset is:

$$
\tilde{v}_{B}=\phi_{1} \tilde{p}_{\text {crop }}+\tilde{v}_{\text {landres }} .
$$

Generally, the residual value $\tilde{v}_{\text {landres }}$ may be related to $\tilde{\theta}$ and $\tilde{\varepsilon}_{A}$, and particularly to $\tilde{\theta}$, because to the extent that $\tilde{\theta}$ is interpreted as factors affecting consumers' wealth, $\tilde{\theta}$ will affect the other uses of the land and hence its residual value. Hence, we assume:

$$
\tilde{v}_{\text {landres }}=\phi_{2} \tilde{\theta}+\tilde{\eta}_{B}
$$

where $\tilde{\eta}_{B} \sim \mathcal{N}\left(0, \sigma_{\eta}^{2}\right)$ (with $\left.\sigma_{\eta}>0\right)$. Both $\tilde{\varepsilon}_{A}$ and $\tilde{\eta}_{B}$ are independent of $\tilde{\theta}$; they may or may not be correlated with each other. Equations (4), (5), and (6) combine to imply that the B-asset's payoff is

$$
\tilde{v}_{B}=\left(\phi_{1}+\phi_{2}\right) \tilde{\theta}+\left(\phi_{1} \tilde{\varepsilon}_{A}+\tilde{\eta}_{B}\right)-\phi_{1}^{2} \bar{x}_{B} .
$$

We can relabel $\left(\phi_{1}+\phi_{2}\right)$ as $\phi$, and $\left(\phi_{1} \tilde{\varepsilon}_{A}+\tilde{\eta}_{B}\right)$ as $\tilde{\varepsilon}_{B}$, which would then give exactly the same asset payoff structure of asset B as in Equation (11). In particular, $\tilde{\varepsilon}_{B}$ is naturally positively correlated to $\tilde{\varepsilon}_{A}$.

\subsection{Other examples}

In the previous subsection, we formally derived a basic setup where our model assumptions arise quite naturally. In this subsection, we briefly describe some other motivating examples for our model without formal derivations. We wish to demonstrate that our basic setup, whereby some investors trade in a broader set of markets than others while prices are generally observable to all investors, is quite general and captures many real-world settings. We provide more general comments in Section 3.3

3.2.1 International markets. Despite the benefit of international diversification, most investors invest only in the domestic market. In fact, "home bias"- the phenomenon that investors allocate a relatively large fraction of their wealth to domestic equities - represents one of the unresolved puzzles in the international finance literature (See Lewis 1999 and Karolyi and Stult 2003 for excellent surveys). Conversely, some investors frequently trade in markets of different countries. For example, a popular strategy of hedge funds is global macro trading that bases its holdings - such as long and short positions in various equity, fixed income, currency, and futures markets-primarily on overall economic and political views of various countries. When they anticipate superior investment opportunity in one market, hedge funds buy securities in this market, and to hedge their risk exposure, they simultaneously sell similar securities in a different market. Mapping into our model, investors who restrict their investments in the domestic market are S-traders, while international arbitrageurs such as global macro hedge funds are L-traders. 
3.2.2 CDS markets. As the most liquid and popular product, CDS accounts for more than two-thirds of all outstanding credit derivatives, which have undergone tremendous growth during the past decade 10 While traditional institutional investors, such as pension funds and insurance companies, typically adopt a buy-and-hold strategy in their investments in cash corporate bonds, hedge funds and proprietary trading desks of investment banks actively participate in the CDS markets. Buying CDS is similar to shorting the underlying corporate bond. The difference between CDS rates and corporate bond yield spreads is the CDS-bond basis. When the basis is negative (positive), hedge funds and proprietary traders typically buy (sell) CDS and, at the same time, long (short) the underlying corporate bond. This is called the CDS-bond basis arbitrage. In this example, the $\mathrm{S}$-traders are traditional investors who trade only corporate bonds, and the L-traders are hedge funds and proprietary traders that trade both corporate bonds and CDS.

3.2.3 Convertible bond markets. A convertible bond is a bond that can be converted into the issuing company's stock in the future. Convertible bond issuance has increased dramatically in recent years, from $\$ 7.8$ billion in 1992 to $\$ 50.2$ billion in 2006 (Securities Data Corporation [SDC], Global New Issues database). The dominant player in this market is convertible bond arbitrage hedge funds, who purchase $70 \%$ to $80 \%$ of the convertible debt offered in primary markets (e.g., Choi, Getmansky, and Tookes 2009). When a hedge fund has favorable information about a company, its common strategy is to buy the company's convertible bonds in hope of exchanging them for stocks when the stock price rises in the future and, at the same time, to short stocks of the same company to hedge itself 11 At the same time, more traditional investors like retail investors and mutual funds typically stay away from the convertiblebonds market. Hence, the S-traders are those investors who trade only stocks, and the L-traders are the hedge-fund type of investors who trade both stocks and convertible bonds.

3.2.4 Index futures markets. Index futures are widely used in the financial markets of many countries. One common strategy is index arbitrage, which is done by simultaneously buying (or selling) a stock index future while selling (or buying) the stocks in that index. The report from the Commodities Future Trading Commission and the Securities and Exchange Commission (CFTC-SEC) (May 2012) identifies one source of the flash crash of May 6, 2012, as those index arbitrageurs who opportunistically buy S\&P 500 futures

10 According to the Bank for International Settlements (BIS), the notional value of outstanding credit derivatives reached $\$ 58$ trillion by the end of 2007 , more than six times that of the corporate bond market.

11 There is an interesting anecdote from 2005, when many hedge funds had long positions in General Motors (GM) convertible bonds and short positions in GM stocks. They suffered huge losses when a billionaire investor tried to buy GM stock and at the same time its debt was being downgraded by credit-ratings agencies. 
contracts (the "E-Mini" contracts) and simultaneously sell products like S\&P 500 exchange-traded funds, or selling individual equities in the S\&P 500, which transferred the selling pressure in the futures market to the equities markets. In this example, individual investors (S-traders) are more likely to concentrate on the trading of the component stock of the index or the stock index, while hedge funds (L-traders) are more likely to engage in index arbitrage by trading in both the equity and index futures markets.

3.2.5 Human capital and entrepreneurship. More generally, our model appeals to the broad hedging activity that entrepreneurs engage in. Since a lot of their human capital is invested in their firms, entrepreneurs may try to hedge this firm-specific risk by short-selling the firm's stock or the stocks of other firms in the same industry. Hence, like the L-traders in our model, their actions may be interpreted as taking speculative positions in their human capital (which is the B-asset) while short-selling related stocks (which are A-assets). At the same time, other traders in the economy have access only to the traded stocks, and so they use them for speculative trading 12

\subsection{Market segmentation and price observability}

The variety of markets covered in the previous two sections share two common features. First, markets are segmented in that L-traders trade both risky assets (A-asset and B-asset) while S-traders trade only one risky asset (A-asset). Therefore, L-traders have a larger investment opportunity set than S-traders. Second, even though S-traders do not trade the B-asset, they can observe the price of the B-asset and make rational inferences from prices. These two features underlie our model. We now explain more generally their joint empirical relevance.

First, in some scenarios, the B-asset is simply not accessible to S-traders. This is most easily seen in the human capital example. Speculators in financial markets simply do not have the ability to make the human capital investments that entrepreneurs or employees are making. Yet, the "prices" or "returns" to this human-capital investment can be easily observed by the speculators. For example, in the case of public companies, SEC requires clear, concise, and understandable disclosure about compensation paid to CEOs, CFOs and certain other high-ranking executive officers. In fact, with the development of the Internet, salaries are increasingly transparent. Many websites and forums provide free salary information by location and occupation. However, even though one can observe the increasing pay to one profession, say, doctors, a person is not able to immediately switch to this profession, as the needed skills require years of training.

12 In a related study, Chen, Miao, and Wang 2010) develop a dynamic incomplete-markets model of entrepreneurial firms, and demonstrate the implications of nondiversifiable risks for entrepreneurs' interdependent portfolio allocation decision. 
Second, many trading strategies - for example, CDS-bond basis arbitrage, convertible bond arbitrage, index arbitrage-typically involve short-selling and the usage of derivatives, which are often used by hedge funds facing fewer regulations (see the discussion in Stul 2007). In contrast, retail investors or traditional institutional investors - that is, mutual funds, pension funds, and insurance companies - typically have more trading constraints. Almazan, Brown, Carlson, and Chapman 2004) provide a comprehensive examination of investment constraints for mutual funds. They document that roughly $70 \%$ of mutual funds explicitly state (in Form N-SAR that they file with the SEC) that they are not permitted to sell short. Koski and Pontiff 1999) find that 79\% of equity mutual funds make no use of derivatives whatsoever (either futures or options). Anecdotal evidence suggests that pension funds also stay away from derivatives and CDS. For example, Erwan Boscher, head of Liability-Driven Investing and Fiduciary Management at AXA Investment Managers, one of the world's largest asset managers, says: "Using market instruments like CDS and out of the money equity puts were suggested as a way of hedging sponsor risks, but we seldom see them implemented because of the cost, liquidity or reputational risks for the sponsor" (Reuters, March 30, 2012). Therefore, it is clear that many traditional investors stay away from many markets, such as derivative markets. At the same time, it is clear that they can observe the prices of derivatives and other related securities from various sources and that they can use these prices to guide their investment decisions.

Third, even without trading constraints, funds typically invest according to their "style." A prominent feature of the financial industry is called "style investing," where assets are categorized into broad classes such as large-cap stocks, value stocks, government bonds, international assets, and so on. An increasing trend is that mutual-fund managers and pension-fund managers identify themselves as following a particular investment style, such as growth, value, or technology Barberis and Shleifer 2003). The performance of a fund style and individual funds can be easily located on websites like Morningstar. However, as documented in Fung and Hsieh 1998), there is little evidence of asset class rotation in mutual fund styles. Therefore, a value fund typically will not invest in corporate bonds, and a domestic fund will not invest in international markets. Hence, while these funds will surely use broad price information to improve their trading strategy, they will not trade as freely across markets and asset styles.

Finally, market segmentation can also arise for other reasons. In the international context, a variety of theories have been put forward to explain the "home bias" puzzle. In his presidential address, Duffie 2010) suggests that due to slow movement of investment capital, many trading opportunities cannot be exploited by investors who want to take advantage of them.

For all these underlying causes, market segmentation emerges as a natural phenomenon we observe in financial markets. At the same time, progress in information technology has considerably increased investors' access to price 
information in real time. Our model thus captures this realistic feature that information "travels" more quickly than capital so that traders can watch the prices of assets that are not in but are related to their portfolios, and adjust their trading strategies accordingly.

That traders learn information from different markets is a common phenomenon. As mentioned in Biais and Hillion, 1994, 747), "market makers in the stock and in the option markets have the same information set; that is, they can monitor perfectly and simultaneously orders and trades in both markets. In most actual exchanges, the stock and the options are traded separately. For example, options on stocks listed on the NYSE are traded on the AMEX or in Chicago. Information flows rapidly across markets, however." Cespa and Foucault 2012) also assume that markets for different assets have become more interconnected as liquidity suppliers in one asset class increasingly rely on the information contained in the prices of other asset classes to set their quotes. Singleton (forthcoming) finds that participants in commodity markets are actively drawing inferences about future spot prices of commodities from the prices in other markets. Sockin and Xiong 2013) construct a model to capture the possibility that information in commodity futures prices can feed back to traders' commodity demand and affect the spot prices.

All the above examples suggest that markets are segmented in terms of the ability to move capital across markets and trade in different markets due to various frictions, but not so much in terms of price information. In other words, capital is relatively segmented and slow moving (e.g., Duffie 2010), but information is relatively integrated and fast moving, and traders actively use this information (e.g., Cespa and Foucaul 2012). This notion of segmentation/integration is very relevant given the improvement of information technology on the one hand and the specialization and delegation of investment on the other hand.

In the next section, we turn to the analysis of our model that features these characteristics and show that in such an environment, traders, who have related pieces of information but have different investment opportunity sets, may wish to trade an asset in different directions, which can reduce price informativeness and therefore have important pricing and learning implications.

\section{Trading and Prices}

We start by analyzing trading behavior and prices in the financial market, given the fraction of S-traders, who choose to become informed. We denote this fraction as $\mu$. The equilibrium concept that we use is the rational expectations equilibrium (REE), as in Grossman and Stiglitz 1980). In equilibrium, traders trade to maximize their expected utility given their information set, where L-traders and informed S-traders know $\left\{\tilde{\theta}, \tilde{p}_{A}, \tilde{p}_{B}\right\}$, while uninformed S-traders know $\left\{\tilde{p}_{A}, \tilde{p}_{B}\right\}$. Prices of assets $\mathrm{A}$ and $\mathrm{B}$ are set to clear the markets. We now turn to a detailed derivation of the equilibrium. 


\subsection{Price functions}

The trading by L-traders and that by informed S-traders are affected by the information set $\left\{\tilde{\theta}, \tilde{p}_{A}, \tilde{p}_{B}\right\}$, while the uninformed S-traders' trading is affected by the information set $\left\{\tilde{p}_{A}, \tilde{p}_{B}\right\}$. In the A-asset market, noise traders demand $\tilde{n}_{A}$. Hence, the price of the A-asset is a function of $\left(\tilde{\theta}, \tilde{p}_{A}, \tilde{p}_{B}, \tilde{n}_{A}\right)$ : $\tilde{p}_{A}=p_{A}\left(\tilde{\theta}, \tilde{p}_{A}, \tilde{p}_{B}, \tilde{n}_{A}\right)$. Similarly, the price of the B-asset is a function of $\left(\tilde{\theta}, \tilde{p}_{A}, \tilde{p}_{B}, \tilde{n}_{B}\right): \tilde{p}_{B}=p_{B}\left(\tilde{\theta}, \tilde{p}_{A}, \tilde{p}_{B}, \tilde{n}_{B}\right)$. Combining $\tilde{p}_{A}=p_{A}\left(\tilde{\theta}, \tilde{p}_{A}, \tilde{p}_{B}, \tilde{n}_{A}\right)$ and $\tilde{p}_{B}=p_{B}\left(\tilde{\theta}, \tilde{p}_{A}, \tilde{p}_{B}, \tilde{n}_{B}\right)$, and solving for $\tilde{p}_{A}$ and $\tilde{p}_{B}$, we expect that both prices are functions of $\left(\tilde{\theta}, \tilde{n}_{A}, \tilde{n}_{B}\right)$.

As is the case in most of the literature, we study linear equilibria-that is, where $\tilde{p}_{A}$ and $\tilde{p}_{B}$ are linear functions of $\left(\tilde{\theta}, \tilde{n}_{A}, \tilde{n}_{B}\right)$ :

$$
\begin{aligned}
& \tilde{p}_{A}=a_{0}+a_{\theta} \tilde{\theta}+a_{A} \tilde{n}_{A}+a_{B} \tilde{n}_{B}, \\
& \tilde{p}_{B}=b_{0}+b_{\theta} \tilde{\theta}+b_{A} \tilde{n}_{A}+b_{B} \tilde{n}_{B},
\end{aligned}
$$

where the coefficients are endogenously determined 13

We first examine the decisions of L-traders and informed S-traders, which in turn determine the information content in prices $\tilde{p}_{A}$ and $\tilde{p}_{B}$. We then solve for the decisions of uninformed S-traders, and finally, we use the market-clearing condition to find the coefficients in the price functions.

\subsection{Traders' demand}

4.2.1 L-traders. L-traders have information $\left\{\tilde{\theta}, \tilde{p}_{A}, \tilde{p}_{B}\right\}$. Let $E\left[\cdot \mid \tilde{\theta}, \tilde{p}_{A}, \tilde{p}_{B}\right]$ denote the expectation operator conditional on their information set. They choose investment in the riskless asset $D_{F}^{L}$, in the A-asset $D_{A}^{L}$ and in the B-asset $D_{B}^{L}$, to maximize their expected utility

$$
E\left[-e^{-\gamma \tilde{W}_{2}^{L}} \mid \tilde{\theta}, \tilde{p}_{A}, \tilde{p}_{B}\right],
$$

from date-2 wealth $\tilde{W}_{2}^{L}$, which is given by

$$
\tilde{W}_{2}^{L}=\tilde{v}_{A} D_{A}^{L}+\tilde{v}_{B} D_{B}^{L}+D_{F}^{L} .
$$

They are subject to the budget constraint

$$
D_{F}^{L}+D_{A}^{L} \tilde{p}_{A}+D_{B}^{L} \tilde{p}_{B}=W_{1}^{L}
$$

where $W_{1}^{L}$ is date-1 wealth of the L-trader. Note that all L-traders will choose the same risky investments $D_{A}^{L}$ and $D_{B}^{L}$ because they have the same information set and because their initial wealth has no effect due to the CARA preference.

13 Note that the prices of the two assets are correlated, as one would expect, given that they are affected by the same fundamental $\tilde{\theta}$ (and also affected by the same shocks to noise trading). However, because the correlation between the residual noise of the two assets is less than perfect (i.e., $\rho \in(0,1)$ ), our model does not feature a no-arbitrage relationship that ties the prices of the two assets together. Traders, who trade the two assets, will always be exposed to some residual risk. For example, take the case of the futures market exhibited in Section 3.1 in which the price of the B-asset (land) is affected by the other uses of land that do not affect the price of the A-asset (futures contract on crops). 
Given the assumptions of CARA preferences and normal distributions, their optimal investments in the risky assets are

$$
\begin{aligned}
& D_{A}^{L}\left(\tilde{\theta}, \tilde{p}_{A}, \tilde{p}_{B}\right)=\frac{\tilde{\theta}-\tilde{p}_{A}}{\gamma\left(1-\rho^{2}\right) \sigma_{\varepsilon A}^{2}}-\frac{\rho\left(\phi \tilde{\theta}-\tilde{p}_{B}\right)}{\gamma\left(1-\rho^{2}\right) \sigma_{\varepsilon A} \sigma_{\varepsilon B}}, \\
& D_{B}^{L}\left(\tilde{\theta}, \tilde{p}_{A}, \tilde{p}_{B}\right)=\frac{\phi \tilde{\theta}-\tilde{p}_{B}}{\gamma\left(1-\rho^{2}\right) \sigma_{\varepsilon B}^{2}}-\frac{\rho\left(\tilde{\theta}-\tilde{p}_{A}\right)}{\gamma\left(1-\rho^{2}\right) \sigma_{\varepsilon A} \sigma_{\varepsilon B}} .
\end{aligned}
$$

In both equations, the first term represents speculation-based trading and the second term represents hedging-motivated trading. For example, the first term in (8) says that L-traders demand more of the A-asset when $\left(\tilde{\theta}-\tilde{p}_{A}\right)$ is high. Note that $\tilde{\theta}-\tilde{p}_{A}=E\left(\tilde{v}_{A} \mid \tilde{\theta}, \tilde{p}_{A}, \tilde{p}_{B}\right)-\tilde{p}_{A}=E\left(\tilde{v}_{A} \mid \tilde{\theta}\right)-\tilde{p}_{A}$ is the difference between the expected future value $\tilde{v}_{A}$ of the A-asset-given L-traders' private information $\tilde{\theta}$-and its prevailing price $\tilde{p}_{A}$, and so if $\left(\tilde{\theta}-\tilde{p}_{A}\right)$ is high, it means that asset $\mathrm{A}$ is undervalued relative to its fundamental, which attracts the Ltraders to buy it. In this sense, the first term in (8) captures L-traders' speculative behavior in the A-asset based on their private information about asset A's payoff $\tilde{v}_{A}$. For a similar reason, the first term in (9) represents L-traders' speculation in the B-asset: they demand more of the B-asset when $\phi \tilde{\theta}-\tilde{p}_{B}=E\left(\tilde{v}_{B} \mid \tilde{\theta}\right)-\tilde{p}_{B}$ is high - that is, when the B-asset's price is low relative to its expected payoff estimated based on L-traders' private information.

The second term in 8 says that L-traders demand less of the A-asset when $\left(\phi \tilde{\theta}-\tilde{p}_{B}\right)$ is high, because then holding the B-asset becomes more profitable (through the first term in (9), and so they reduce their demand for the A-asset to hedge their speculative positions in the B-asset, just in case that their speculation on the B-asset fails. Hence, this term represents their hedging-motivated trading in the A-asset. Again, similarly, the second term in 9 represents the hedging component in L-traders' demand for the B-asset.

More important, in both markets, the speculative trading responds positively to the change in information $\tilde{\theta}$, while the hedging-motivated trading responds negatively to the change in information $\tilde{\theta}$. Their relative strength determines the overall sensitivity of L-traders' trading in a particular asset to information $\tilde{\theta}$. We define

$$
\begin{gathered}
\delta_{A}^{L} \equiv \frac{\partial D_{A}^{L}\left(\tilde{\theta}, \tilde{p}_{A}, \tilde{p}_{B}\right)}{\partial \tilde{\theta}}=\frac{1-\phi \rho \sigma_{\varepsilon A} \sigma_{\varepsilon B}^{-1}}{\gamma\left(1-\rho^{2}\right) \sigma_{\varepsilon A}^{2}} \\
\delta_{B}^{L} \equiv \frac{\partial D_{B}^{L}\left(\tilde{\theta}, \tilde{p}_{A}, \tilde{p}_{B}\right)}{\partial \tilde{\theta}}=\frac{\phi-\rho \sigma_{\varepsilon A}^{-1} \sigma_{\varepsilon B}}{\gamma\left(1-\rho^{2}\right) \sigma_{\varepsilon B}^{2}},
\end{gathered}
$$

to capture these overall sensitivities in the two markets, respectively. If $\delta_{A}^{L}>0$, the speculative trading motive dominates the hedging trading motive in the A-asset, so that an increase in $\tilde{\theta}$ will cause L-traders to demand more of the A-asset, and we say that in this case they trade asset A "mainly for speculation." In contrast, if $\delta_{A}^{L}<0$, the opposite is true, and we say that L-traders trade asset 
A “mainly for hedging." A similar definition applies to $\delta_{B}^{L}$ : a positive (negative) sign of $\delta_{B}^{L}$ indicates that an L-trader trades the B-asset mainly for speculation (hedging) 14

4.2.2 Informed S-traders. Informed S-traders also have information set $\left\{\tilde{\theta}, \tilde{p}_{A}, \tilde{p}_{B}\right\}$, but have a limited trading set. That is, they choose riskless asset holdings $D_{F}^{I}$ and A-asset holdings $D_{A}^{I}$ to maximize

$$
E\left[-e^{-\gamma \tilde{W}_{2}^{I}} \mid \tilde{\theta}, \tilde{p}_{A}, \tilde{p}_{B}\right],
$$

subject to

$$
D_{F}^{I}+D_{A}^{I} \tilde{p}_{A}=W_{1}^{I} \text { and } \tilde{W}_{2}^{I}=\tilde{v}_{A} D_{A}^{I}+D_{F}^{I},
$$

where $W_{1}^{I}$ and $\tilde{W}_{2}^{I}$ are, respectively, an informed S-trader's wealth at dates 1 and 2. Given the assumptions of CARA preference and normal distributions, their optimal holdings in the risky A-asset are

$$
D_{A}^{I}\left(\tilde{\theta}, \tilde{p}_{A}, \tilde{p}_{B}\right)=\frac{E\left(\tilde{v}_{A} \mid \tilde{\theta}, \tilde{p}_{A}, \tilde{p}_{B}\right)-\tilde{p}_{A}}{\gamma V A R\left(\tilde{v}_{A} \mid \tilde{\theta}, \tilde{p}_{A}, \tilde{p}_{B}\right)}=\frac{\tilde{\theta}-\tilde{p}_{A}}{\gamma \sigma_{\varepsilon A}^{2}} .
$$

In particular, informed S-traders engage in speculative-based trading only in asset A, and they always increase their demand for this asset following an increase in $\tilde{\theta}$. Specifically, the sensitivity of their demand for the A-asset to an increase in $\tilde{\theta}$ is captured by the following variable:

$$
\delta_{A}^{I} \equiv \frac{\partial D_{A}^{I}\left(\tilde{\theta}, \tilde{p}_{A}, \tilde{p}_{B}\right)}{\partial \tilde{\theta}}=\frac{1}{\gamma \sigma_{\varepsilon A}^{2}},
$$

and $\delta_{A}^{I}$ is always positive. This is in sharp contrast to the sensitivity $\delta_{A}^{L}$ of L-traders' trading in the A-asset, which can be either positive or negative, depending on whether speculation or hedging purpose dominates. As we will show shortly, in the case of $\delta_{A}^{L}<0$, in the A-market, L-traders and informed S-traders trade on information $\tilde{\theta}$ differently $\left(\delta_{A}^{L}<0\right.$ and $\left.\delta_{A}^{I}>0\right)$, and their aggregate demand in the A-asset can become very insensitive to information, reducing the informativeness of the price system.

4.2.3 Uninformed S-traders. Uninformed S-traders observe only the realizations of prices, $\tilde{p}_{A}$ and $\tilde{p}_{B}$. They choose riskless asset holdings $D_{F}^{U}$ and A-asset holdings $D_{A}^{U}$ to maximize

$$
E\left[-e^{-\gamma \tilde{W}_{2}^{U}} \mid \tilde{p}_{A}, \tilde{p}_{B}\right]
$$

14 Note that it is possible that an L-trader trades both assets mainly for speculation, or that he trades one asset mainly for speculation and the other one mainly for hedging. However, as what we would expect, it is not possible that he trades both assets mainly for hedging. 
subject to

$$
D_{F}^{U}+D_{A}^{U} \tilde{p}_{A}=W_{1}^{U} \text { and } \tilde{W}_{2}^{U}=\tilde{v}_{A} D_{A}^{U}+D_{F}^{U},
$$

where $W_{1}^{U}$ and $\tilde{W}_{2}^{U}$ are, respectively, an uninformed S-trader's wealth at dates 1 and 2. The demand of the uninformed S-traders for the risky A-asset is

$$
D_{A}^{U}\left(\tilde{p}_{A}, \tilde{p}_{B}\right)=\frac{E\left(\tilde{v}_{A} \mid \tilde{p}_{A}, \tilde{p}_{B}\right)-\tilde{p}_{A}}{\gamma \operatorname{VAR}\left(\tilde{v}_{A} \mid \tilde{p}_{A}, \tilde{p}_{B}\right)} .
$$

Using the analysis of the behavior of L-traders and informed S-traders, the two risky asset prices imply two public signals to the uninformed S-traders. Specifically, the market-clearing condition in the B-asset market is:

$$
\lambda D_{B}^{L}\left(\tilde{\theta}, \tilde{p}_{A}, \tilde{p}_{B}\right)+\tilde{n}_{B}=\bar{x}_{B},
$$

that is, the sum of demands from L-traders and from noise traders equals the aggregate supply. Substituting L-traders' demand for the B-asset in 9) into the above condition, moving the prices $\tilde{p}_{A}$ and $\tilde{p}_{B}$ to the RHS, and dividing both sides by $\lambda \delta_{B}^{L}$, we find

$$
\tilde{\theta}+\left(\lambda \delta_{B}^{L}\right)^{-1} \tilde{n}_{B}=\left(\lambda \delta_{B}^{L}\right)^{-1} \bar{x}_{B}-\left(\lambda \delta_{B}^{L}\right)^{-1} \frac{\lambda \rho \tilde{p}_{A}}{\gamma\left(1-\rho^{2}\right) \sigma_{\varepsilon A} \sigma_{\varepsilon B}}+\left(\lambda \delta_{B}^{L}\right)^{-1} \frac{\lambda \tilde{p}_{B}}{\gamma\left(1-\rho^{2}\right) \sigma_{\varepsilon B}^{2}},
$$

which is observable to uninformed S-traders, since the prices $\tilde{p}_{A}$ and $\tilde{p}_{B}$ are public information and all other constants are common knowledge. So, 16 represents the following public signal to the uninformed S-traders:

$$
\tilde{s}_{B} \equiv \tilde{\theta}+k_{B}^{-1} \tilde{n}_{B}, \text { with } k_{B}=\lambda \delta_{B}^{L} .
$$

Similarly, using the market-clearing condition in the A-asset market,

$$
\lambda D_{A}^{L}\left(\tilde{\theta}, \tilde{p}_{A}, \tilde{p}_{B}\right)+\mu D_{A}^{I}\left(\tilde{\theta}, \tilde{p}_{A}, \tilde{p}_{B}\right)+(1-\mu) D_{A}^{U}\left(\tilde{p}_{A}, \tilde{p}_{B}\right)+\tilde{n}_{A}=\bar{x}_{A},
$$

and the expressions for $D_{A}^{L}\left(\tilde{\theta}, \tilde{p}_{A}, \tilde{p}_{B}\right)$ and $D_{A}^{I}\left(\tilde{\theta}, \tilde{p}_{A}, \tilde{p}_{B}\right)$ in 8 and 12 , we can obtain another public signal to the uninformed S-traders:

$$
\tilde{s}_{A} \equiv \tilde{\theta}+k_{A}^{-1} \tilde{n}_{A}, \text { with } k_{A}=\lambda \delta_{A}^{L}+\mu \delta_{A}^{I} .
$$

Hence, by Equations 17 and 19, and after applying Bayes' rule, we have

$$
V A R\left(\tilde{v}_{A} \mid \tilde{p}_{A}, \tilde{p}_{B}\right)=V A R\left(\tilde{\theta} \mid \tilde{s}_{A}, \tilde{s}_{B}\right)+\sigma_{\varepsilon A}^{2},
$$

and

$$
E\left(\tilde{v}_{A} \mid \tilde{p}_{A}, \tilde{p}_{B}\right)=V A R\left(\tilde{\theta} \mid \tilde{s}_{A}, \tilde{s}_{B}\right)\left(k_{A}^{2} \sigma_{n A}^{-2} \tilde{s}_{A}+k_{B}^{2} \sigma_{n B}^{-2} \tilde{s}_{B}\right),
$$

where

$$
V A R\left(\tilde{\theta} \mid \tilde{s}_{A}, \tilde{s}_{B}\right)=\left(\sigma_{\theta}^{-2}+k_{A}^{2} \sigma_{n A}^{-2}+k_{B}^{2} \sigma_{n B}^{-2}\right)^{-1} .
$$

Plugging (20) and 21) into (14), we get the demand of uninformed traders. 


\subsection{Market clearing}

As mentioned above, in equilibrium the sum of demands has to equal the supply in both risky assets. For the A-asset, the market-clearing condition is given by Equation [18), while for the B-asset, it is given by Equation 15]. Note that by Walras' law, given that the markets for the risky assets clear and the budget constraints hold, the market of the riskless asset also clears 15

Plugging (8)-144 into (15) and (18), and solving for the prices $\tilde{p}_{A}$ and $\tilde{p}_{B}$, we prove the following proposition.

Proposition 1. For any given $\mu>0$, there exists a unique linear REE in which

$$
\begin{aligned}
& \tilde{p}_{A}=a_{0}+a_{\theta} \tilde{\theta}+a_{A} \tilde{n}_{A}+a_{B} \tilde{n}_{B}, \\
& \tilde{p}_{B}=b_{0}+b_{\theta} \tilde{\theta}+b_{A} \tilde{n}_{A}+b_{B} \tilde{n}_{B} .
\end{aligned}
$$

The coefficients $a_{0}, a_{\theta}, a_{A}, a_{B}, b_{0}, b_{\theta}, b_{A}$, and $b_{B}$ are given as a function of the exogenous parameters of the model in the proof in Appendix A.

\section{Speculation, Hedging, and Price Informativeness}

The interesting aspect of the setup studied in our paper is the hierarchy in investment opportunities - namely, only L-traders can trade the risky B-assetand the resulting interesting possibility of $\delta_{A}^{L}<0$ and $\delta_{A}^{I}>0$, i.e., that L-traders and informed S-traders can trade the common risky A-asset differently in response to information $\tilde{\theta}$. In this section, we study the implications of this feature for the informativeness of the price system and hence asset prices at the trading stage when the size $\mu$ of informed S-traders is exogenous. In the next section, we will endogenize $\mu$ to examine the implications for the information acquisition decisions.

In this section, we particularly focus on the effect of the parameters $\lambda, \mu$, and $\phi$. Recall that $\lambda$ and $\mu$, respectively, capture the sizes of the L-traders population and the informed S-traders population, who can possibly trade the A-asset against each other in response to the same information, and thus these two parameters will determine the relative strength of the two possibly opposing forces of incorporating information $\tilde{\theta}$ into the price system. Parameter $\phi$ is the sensitivity of the B-asset to the information, which is associated with the advantage held by the L-traders, and it represents the strength of L-traders' enlarged investment opportunity set in financial markets.

\subsection{Price informativeness}

In our measurement of price informativeness we try to capture the amount of uncertainty about $\tilde{\theta}$ that is reduced by observing the two prices $\tilde{p}_{A}$ and $\tilde{p}_{B}$.

15 Recall that the price of the riskless asset was normalized to one, such that this asset is essentially the numeraire. 
This is similar to the amount of information gleaned by the uninformed traders from the prices. Hence, we define price informativeness as:

$$
I \equiv \frac{V A R(\tilde{\theta})}{V A R\left(\tilde{\theta} \mid \tilde{p}_{A}, \tilde{p}_{B}\right)}-1=k_{A}^{2} \frac{\sigma_{\theta}^{2}}{\sigma_{n A}^{2}}+k_{B}^{2} \frac{\sigma_{\theta}^{2}}{\sigma_{n B}^{2}},
$$

where the second equality follows from Equation 22). This concept is consistent with using $k$ to measure the informativeness of a signal $\left(\tilde{\theta}+k^{-1} \tilde{n}\right)$. The two endogenous parameters $k_{A}$ and $k_{B}$ (that depend on $\lambda, \mu$, and $\phi$ ) are taken from 17) and 19):

$$
\begin{aligned}
& k_{A}=\lambda \delta_{A}^{L}+\mu \delta_{A}^{I}=\frac{\lambda\left(1-\phi \rho \sigma_{\varepsilon A} \sigma_{\varepsilon B}^{-1}\right)}{\gamma\left(1-\rho^{2}\right) \sigma_{\varepsilon A}^{2}}+\frac{\mu}{\gamma \sigma_{\varepsilon A}^{2}}, \\
& k_{B}=\lambda \delta_{B}^{L}=\frac{\lambda\left(\phi \sigma_{\varepsilon B}^{-1}-\rho \sigma_{\varepsilon A}^{-1}\right)}{\gamma\left(1-\rho^{2}\right) \sigma_{\varepsilon B}},
\end{aligned}
$$

where the second equalities in the above two equations follow from the definitions of $\delta_{A}^{L}, \delta_{B}^{L}$, and $\delta_{A}^{I}$ in Equations 10, 111, and 13.

Parameters $k_{A}$ and $k_{B}$ represent the information injected by the informed $\mathrm{L}$ - and S-traders into the price system. In particular, $\lambda \delta_{A}^{L}$ in $k_{A}$ represents the trading of L-traders in the A-asset, while $\mu \delta_{A}^{I}$ represents the trading of informed S-traders. As we mentioned above, the key insights of our model stem from the fact that these two terms may have opposite signs, indicating that, in response to $\tilde{\theta}, \mathrm{L}$-traders and informed S-traders are trading the A-asset in opposite directions. This will happen when the hedging-based trading of L-traders in the A-asset dominates their speculative-based trading in this asset, so that $\delta_{A}^{L}<0$. Then, an increase in $\tilde{\theta}$ causes them to increase their demand for the B-asset for speculative reasons and at the same time reduce their demand for the A-asset to hedge their position in the B-asset. Since S-traders only trade the A-asset, they only engage in speculative-based trading in this asset, and so they always increase their demand for this asset following an increase in $\tilde{\theta}$ - that is, it is always the case that $\delta_{A}^{I}>0$. The fact that different traders trade in opposite directions in response to information reduces the ability to infer information from the price. This may generate some interesting implicationsfor example, that increasing the size of the informed-traders population (either $\lambda$, the size of the L-traders population, or $\mu$, the size of the informed S-traders population) may reduce the informativeness of the price system. This is against the implications of traditional models, where having more informed traders is beneficial for informativeness.

Specifically, we have the following proposition, which formalizes the effect of the sizes $\lambda$ and $\mu$ of the informed-traders population on price informativeness.

\section{Proposition 2.}

(i) If $\left(\phi \rho \sigma_{\varepsilon A} \sigma_{\varepsilon B}^{-1}\right)>1$ and $\lambda$ is sufficiently small, then $\frac{\partial I}{\partial \lambda}<0$; that is, price informativeness decreases in the size of the L-traders population. Otherwise, $\frac{\partial I}{\partial \lambda}>0$. 
(ii) If $\left(\phi \rho \sigma_{\varepsilon A} \sigma_{\varepsilon B}^{-1}\right)>1$ and $\mu$ is sufficiently small, then $\frac{\partial I}{\partial \mu}<0$; that is, price informativeness decreases in the size of the informed S-traders population. Otherwise, $\frac{\partial I}{\partial \mu}>0$.

As the proposition shows, increasing the size $(\lambda$ or $\mu)$ of the informedtraders population will have a negative effect on price informativeness when two conditions hold. The first condition is that, in response to information $\tilde{\theta}$, the L-traders, who have a larger investment opportunity set and can trade both risky assets, are trading the A-asset in opposite direction to the informed S-traders (i.e., $\delta_{A}^{L}<0$ and $\delta_{A}^{I}>0$ ). By Equation 10), this occurs when

$$
\delta_{A}^{L}<0 \Leftrightarrow\left(\phi \rho \sigma_{\varepsilon A} \sigma_{\varepsilon B}^{-1}\right)>1,
$$

and so the hedging-motivated trade by the L-traders is sufficiently strong.

It is useful to understand in detail when this condition holds, as there are four parameters that go into it. First, this condition is more likely to hold when $\phi$ is large, since $\phi$ captures the sensitivity of the B-asset to information, and so when it is large, L-traders are more likely to take a speculative position in the B-asset and a hedging position in the A-asset. Second, the condition is more likely to hold when the correlation $\rho$ between the noise terms of the two assets is larger, as then hedging plays a greater role. Third, the condition is more likely to hold when $\sigma_{\varepsilon A}$ is larger, and so there is more noise in the payoff of the A-asset. In this case, the A-asset becomes more suitable for hedging than for speculating. Fourth, for a similar reason, the condition is more likely to hold when $\sigma_{\varepsilon B}$ is smaller. Overall, condition (26) is the key in our paper, as it summarizes when L-traders trade the A-asset based on the signal $\tilde{\theta}$ primarily for hedging rather than for speculative purposes.

The second condition for $\lambda$ or $\mu$ to have a negative effect on price informativeness is that it be sufficiently small. Take the effect of $\lambda$ in part (i) of Proposition 2 as an example. When $\lambda$ is large, trading by the L-traders is dominant for the determination of price informativeness, and so when there is more of it, price informativeness increases. But, when $\lambda$ is small, the trading by the informed S-traders becomes more important and it is the one that determines price informativeness, and so the fact that more L-traders trade against the informed $\mathrm{S}$-traders reduces the overall informativeness. This result suggests that, under the above-mentioned conditions in part (i) of Proposition 2 increasing the presence of L-traders-for example, commodity hedgers in commodity futures markets or hedge funds in other financial markets-will reduce price informativeness.

Next, we look at the effect of $\phi$ on the informativeness of the price system. This is summarized in the following proposition.

Proposition 3. For a sufficiently small $\phi, \frac{\partial I}{\partial \phi}<0$; that is, the informativeness of the price system decreases in the sensitivity of the B-asset to information. For a sufficiently large $\phi, \frac{\partial I}{\partial \phi}>0$. 
According to the proposition, an increase in the sensitivity of the B-asset to the signal $\tilde{\theta}$ may lead to a reduction in the overall informativeness of the price system. First, note that in a model with one asset and no endogenous hedging, this would not be the case. In such a model, when the asset is more sensitive to the information, traders trade more aggressively on the information, leading to greater informativeness. But, in our model, this intuition might get reversed. In general, when $\phi$ is low, in response to the signal $\tilde{\theta}$, both types of traders use the A-asset for speculation, and L-traders use the B-asset for hedging. Then, prices are relatively informative. But, then, an increase in $\phi$ induces L-traders to start speculating more with the B-asset and hedging more with the A-asset, and this goes against the direction of trade of S-traders and reduces price informativeness. Hence, the implication is that having a more informationally sensitive asset that is only available to some informed traders, might reduce overall price informativeness.

\subsection{Cost of capital}

One important implication of price informativeness is its effect on asset prices. We will focus our analysis on the A-asset, and examine the following variable:

$$
C C \equiv E\left(\tilde{v}_{A}-\tilde{p}_{A}\right)
$$

that is, the expected difference between the cash flow generated by the Aasset and its price, where the expectation is computed with respect to the prior distribution (before $\tilde{\theta}$ is observed). The variable $C C$ is of interest to various markets mentioned in Section 3 For example, in the commodity futures market, it corresponds to the futures risk premium per share, or the negative of futures price bias, which has attracted much attention of the futures market literature. In many other motivating examples listed in Section 3.2 the A-asset is a stock issued by the firm, whereas the B-asset is likely to be a derivative that only certain traders have access to. So, the variable $C C$ is "the return that an outside observer could compute per share" Easley and O'Hara 2004, 1561), and hence it is the cost of capital per share that the firm faces when issuing the stock. For this reason, we follow the literature and refer to variable $C C$ as the "cost of capital."

From the proof of Proposition 1 we then know that

$$
C C=\frac{\bar{x}_{A}+\left(\rho \sigma_{\varepsilon A}^{-1} \sigma_{\varepsilon B}\right) \bar{x}_{B}}{\Omega},
$$

where $\Omega$ is an endogenous coefficient as defined in the proof of Proposition 1

$$
\Omega=\frac{\lambda+\mu}{\gamma \sigma_{\varepsilon A}^{2}}+\frac{1-\mu}{\gamma V A R\left(\tilde{v}_{A} \mid \tilde{p}_{A}, \tilde{p}_{B}\right)},
$$

which represents the average forecast precision about future payoff of asset A. The first term on the right-hand side of 29] captures the residual risk borne 
by the informed traders - that is, L-traders and informed S-traders-due to the uncertainty about $\tilde{\varepsilon}_{A}$. The second term captures the risk borne by the uninformed S-traders, who face additional risk due to not knowing $\tilde{\theta}$ (and trying to infer it from the price). Combining (29) with 28), we can see that the cost of capital increases in the risk that traders are exposed to per unit of the asset and in the supply of the asset (which increases the total amount of risk that has to be absorbed). It decreases in the size of the traders population, since when there are more traders, the risk can be shared more broadly 16

The implications of price informativeness are then clear. From 23, 28), and (29) and since $V A R\left(\tilde{v}_{A} \mid \tilde{p}_{A}, \tilde{p}_{B}\right)=V A R\left(\tilde{\theta} \mid \tilde{p}_{A}, \tilde{p}_{B}\right)+\sigma_{\varepsilon A}^{2}$, an increase in price informativeness leads to a decrease in the cost of capital, as uninformed S-traders are exposed to less risk when they observe more information in the price. Then, the following corollary immediately follows from Proposition 3

Corollary 1. For a sufficiently small $\phi, \frac{\partial C C}{\partial \phi}>0$; that is, the cost of capital increases in the sensitivity of the B-asset to information. For a sufficiently large $\phi, \frac{\partial C C}{\partial \phi}<0$.

Similarly, we can analyze the effect of the size $(\lambda$ or $\mu)$ of the informedtraders population on the cost of capital. This is, however, not so obvious, since $\lambda$ and $\mu$ affect the cost of capital not only via the informativeness of the price. There is also a direct effect, by which an increase in the size of the informedtraders population implies that there is less risk to be spread, and so the cost of capital decreases. Still, we can prove the following proposition.

\section{Proposition 4.}

(i) If $\lambda$ is sufficiently small and either $\phi$ is sufficiently large or $\sigma_{\varepsilon B}$ is sufficiently small, then $\frac{\partial C C}{\partial \lambda}>0$; that is, the cost of capital increases in the size of the L-traders population. Otherwise, $\frac{\partial C C}{\partial \lambda}<0$.

(ii) If $\mu$ is sufficiently small and $\phi$ is sufficiently large, then $\frac{\partial C C}{\partial \mu}>0$; that is, the cost of capital increases in the size of the informed S-traders population. Otherwise, $\frac{\partial C C}{\partial \mu}<0$.

The intuition is simple. Regarding part (i), we know from part (i) of Proposition 2 that when $\lambda$ is small and when L-traders use the A-asset primarily for hedging purposes, an increase in the size of the L-traders population reduces price informativeness, and this has a positive effect on the cost of capital. This effect will dominate the direct negative effect of $\lambda$ on the cost of capital when traders have a strong incentive to speculate in the B-asset and hedge with the A-asset-that is, when either $\phi$ is sufficiently large or $\sigma_{\varepsilon B}$ is sufficiently small. A similar intuition explains part (ii) of Proposition 4

16 This is only the direct effect. As we already know, the size of the traders population affects the informativeness of the price, and hence has an additional indirect effect on the cost of capital. 


\subsection{Empirical and policy implications}

The analysis thus far has revealed the unique implications coming out of our model: namely, because of segmentation, different traders trade a given asset for different purposes - that is, speculation versus hedging — and respond differently to the same information. This affects the informativeness of the price system and the cost of capital. We now describe empirical and policy implications coming out of this analysis for some of the applications covered in Section 3

5.3.1 Futures risk premium. Relying on the setup in Section 3.1 our analysis helps to understand price determination in commodity futures markets. There is a long-standing literature on the determinants of commodity futures premiumthat is, the average difference between the future spot price of the commodity and the current commodity futures price. The theory of normal backwardation Keynes 1930) states that speculators, who take the long side of a commodity futures position, require a risk premium for hedging the spot price exposure of producers. Hence, the futures price will be below the expected future spot price. Hirshleifen 1988a, 1988b studies the interaction between hedgers and arbitrageurs in determining futures premium. The theory of storage (see, e.g., Gorton, Hayashi, and Rouwenhorst 2013) links this premium to inventory management.

The literature on commodity futures markets did not pay much attention to asymmetric information and learning and the effect they may have on prices and risk premia. Going back to Grossman and Stiglitz 1980, asymmetric information and learning have been known to have a major effect on prices in general financial markets, but, by and large, this has not been applied to the context of commodity futures markets 17 As we argue in Section 3.1 and following the literature on commodity futures markets, one important feature of such markets is that they are segmented, given that speculators trade only the commodity futures, while commodity producers and hedgers trade the futures contracts but also the inputs and commodities themselves. This feature is captured well by our model, and so our model is a natural application of the Grossman-Stiglitz framework to the context of commodity futures markets. Hence, our paper can shed light on the commodity futures premium from the angle of asymmetric information and learning. This emphasis on the informational channel is consistent with the recent empirical evidence provided by Singleton (forthcoming), who shows that participants in commodity-related markets actively collect information from prices.

According to the setup provided in Section 3.1 the cost of capital $C C$ of the A-asset is the commodity futures premium. This is the difference between the

17 Two exceptions are Stein 1987) and Sockin and Xiong 2013), who study how information is transferred across commodity-related markets. 
expected payoff and the current price of the commodity futures contract. Given that the futures contract has an aggregate supply of $\bar{x}_{A}=0$, Equation 28 yields $C C=\frac{\rho \bar{x}_{B} \sigma_{\varepsilon B} \sigma_{\varepsilon A}^{-1}}{\Omega}>0$; that is, "backwardation" holds in our setup. This is because on average, L-traders hedge by shorting asset $\mathrm{A}$ in our economy, and, as shown by Equation A2 in Appendix A, their overall average hedging pressure is $\rho \bar{x}_{B} \sigma_{\varepsilon B} \sigma_{\varepsilon A}^{-1} 18$ The futures premium will then be this hedging pressure divided by the average forecast precision about the future commodity payoff, $\Omega=\frac{\lambda+\mu}{\gamma \sigma_{\varepsilon A}^{2}}+$ $\frac{1-\mu}{\gamma V A R\left(\tilde{v}_{A} \mid \tilde{p}_{A}, \tilde{p}_{B}\right)}$. Our analysis reveals the effect of changes in the population of informed traders $(\lambda$ and $\mu)$ on this average forecast precision and hence on the futures premium; see Proposition 4

More specifically, our results on the size $\mu$ of informed S-traders in Propositions 2 and 4 demonstrate the implications of the financialization of commodity futures markets for the futures risk premium. In recent years, financial institutions have greatly increased their investments in commodity futures, which can be viewed as an increase in the parameter $\mu$. Propositions 2 and 4 state that increasing $\mu$ has a non-monotone effect on price informativeness and the cost of capital (i.e., futures premium). In particular, when $\mu$ is small, the increase in $\mu$ can reduce informativeness and increase the futures premium, which might be perceived as an undesirable outcome.

For empirical testing of our model, data on the population of traders are readily available from CFTC. For every futures market with a certain level of market activity, prior to September 2009, the CFTC's weekly Commitment of Traders (COT) reports provide information on the open interest for two categories of traders: "commercial" (L-traders) versus "non-commercial" (Straders). The "commercial group" engaged in business activities hedged by the use of the futures or option markets, and the "non-commercial" group aggregates various types of mostly financial traders, such as hedge funds, mutual funds, floor brokers, and so on. Since September 4, 2009, COT reports further split commercials between "traditional" commercials (producers, processors, commodity wholesalers or merchants, etc.) and commodity swap dealers. They also now differentiate between managed money traders (i.e., hedge funds) and "other non-commercial traders."

5.3.2 Hedge fund regulation. Hedge funds serve as the L-traders in many motivating examples listed in Section 3.2. The unique feature about hedge

18 Specifically, the group demand of L-traders for the A-asset is $\lambda D_{A}^{L}\left(\tilde{\theta}, \tilde{p}_{A}, \tilde{p}_{B}\right)=\frac{\lambda\left(\tilde{\theta}-\tilde{p}_{A}\right)}{\gamma \sigma_{\varepsilon A}^{2}}-\frac{\rho\left(\bar{x}_{B}-\tilde{n}_{B}\right) \sigma_{\varepsilon B}}{\sigma_{\varepsilon A}}$. This expression is consistent with Hirshleifer's (1988b, 1212-1213) decomposition of the optimal futures position into two components - that is, one speculation-based component to exploit the expected profit that can be achieved when futures premium is non-zero and one hedging-based component for risk reduction. The average hedging-based component is $E\left[-\frac{\rho\left(\bar{x}_{B}-\tilde{n}_{B}\right) \sigma_{\varepsilon B}}{\sigma_{\varepsilon A}}\right]=-\rho \bar{x}_{B} \sigma_{\varepsilon B} \sigma_{\varepsilon A}^{-1}$. 
funds is that they trade across many markets, including stock markets, bond markets, derivative markets, and so on. This is in contrast to retail investors and traditional institutional investors (mutual funds and pension funds) who tend to focus on traditional markets and within certain styles of investment (and hence will fit the definition of S-traders in our model). On the policy front, our model speaks to the regulation of hedge funds, which is a very hotly debated topic these days. Propositions 2 and 4 state that the effect of increasing hedge fund presence depends on its current trading size $\lambda$. Holding other things constant, the increase in trading by hedge funds is more likely to be detrimental to informational efficiency when their current size in the market is small. It is in this case that their trading against the direction of trade of others that confuses the market and reduces price efficiency.

This result is in contrast to the traditional argument stating that if the trading of hedge funds is small, it will do no harm to the market. For example, after the 1997 Asian Currency Crisis, the International Monetary Fund was called upon to study the effect of hedge funds on markets, leading to a study by Eichengreen et al. 1998). Eichengreen et al. 1998) interviewed market participants to obtain estimates of hedge fund positions, and argued that there is little reason to believe that hedge funds are more likely to overwhelm a market than other large traders, as the capital available to hedge funds is small compared with that available to other large investors such as commercial banks, investment banks, insurance companies, and corporations. The informational channel highlighted in our model suggests that the trading by hedge funds can negatively affect the efficiency of prices through affecting the trading of other market participants who infer information from prices. This is particularly true when the size of the trading of hedge funds is small. Specifically, the small trading of hedge funds can make other market participants confused about the true fundamental value, and so prices can become inefficient and the market can be very volatile (which will be explained in the next section analyzing the information market).

As far as empirical analysis is concerned, our model offers a number of predictions regarding the effect of the magnitude of hedge fund activities on market efficiency, risk premium, and so on. Coming up with an empirical proxy for $\lambda$ can be challenging given that hedge funds are not obliged to report positions to regulators. Fung and Hsieh 2000) use the performance data of hedge funds to estimate their exposures during a number of major market events. Choi, Getmansky, and Tookes 2009) use changes in equity short interest following convertible bond issuance to identify convertible bond arbitrage activity of hedge funds. Another proxy for $\lambda$ can be obtained through the $13 \mathrm{~F}$ institutional ownership data (e.g., Agarwal et al. 2013.). Finally, it is well known that hedge funds' trading strategies heavily depend on leverage. Therefore, if one is interested in conducting an aggregate timeseries analysis, a plausible measure for $\lambda$ is the ease of hedge funds' access to capital. In practice, one can use the growth in intermediaries' assets 
relative to household assets as suggested in Etula 2010) and Adrian and Shin 2010.

5.3.3 The effect of derivatives trading. Since the B-asset is a derivative asset in many of the scenarios described in Section 3.2 Propositions 2 and 4 provide a framework for examining the effect of derivatives trading on the main underlying market. There has been a long debate on whether derivative markets benefit or harm the market of the underlying assets (see the survey in Mayhew 2000). Recently, with the rapid growth of derivative markets, hedge funds, and multi-security trading strategies, the question of how derivative markets affect the primary market quality has re-emerged as a central issue of debate among academics and policy makers. Notably, the CDS market has been particularly controversial 19 A popular view is that the CDS markets may have contributed to the recent credit crisis, which has led George Soros and others to call for most or all trading in CDS to be banned.

Several empirical studies have been conducted to examine the effect of CDS trading on the underlying corporate bond market. Li, Zhang, and Kim 2011 provide a comprehensive empirical analysis on the implication of CDS-bond basis arbitrage for the pricing of corporate bonds. They show that arbitrageurs introduce new risks into the corporate bond market, which was dominated by passive investors before the existence of CDS. Using an extensive sample of CDS and bond trades over 2002-2008, Das, Kalimipalli, and Nayak 2011) find that the trading of CDS was largely detrimental, making bond markets less efficient. In a systematic and informative study, Boehmer, Chava, and Tookes 2012) provide evidence that the trading in different derivative markets affects the equity market in different ways. Firms generally benefit from the equity options market in that they have more efficient stock prices. By contrast, firms with traded CDS contracts have less efficient stock prices. The existence of publicly traded bonds derivatives has a more mixed, but generally negative effect.

Why does the trading of different derivatives have different effects on the main market? According to our model, there are different parameters characterizing the derivative asset (the B-asset): the coefficient on the fundamental in its asset payoff $(\phi)$, the correlation between the two error terms of the A-asset and B-asset $(\rho)$, the variance of noise in the B-asset $\left(\sigma_{\varepsilon B}\right)$, and the mass of L-traders $(\lambda)$. These parameters will affect whether the trading in a derivative market (B-asset market) will harm or improve overall price

19 See, e.g., Testimony Concerning Credit Default Swaps by Erik Sirri, Director, Division of Trading and Markets, U.S. Securities and Exchange Commission, Before the House Committee on Agriculture, October 15, 2008: "The SEC has a great interest in the CDS market because of its impact on the debt and cash equity securities markets and the Commission's responsibility to maintain fair, orderly, and efficient securities markets. These markets are directly affected by CDSs due to the interrelationship between the CDS market and the claims that compose the capital structure of the underlying issuers on which the protection is written. In addition, we have seen CDS spreads move in tandem with falling stock prices, a correlation that suggests that activities in the OTC CDS market may in fact be spilling over into the cash securities markets." 
efficiency. Hence, since different derivative markets might have systematic differences in these model parameters, these can help explain their different effects on the underlying market. Conducting a sharp empirical test informed by our theory will require one to get a handle on the empirical proxies for the parameters $\phi, \rho, \sigma_{\varepsilon A}$, and $\lambda$ and test our main propositions.

\section{Learning Complementarities, Multiplicity, and Price Jumps}

\subsection{Information market and learning complementarities}

After analyzing the trading decisions and price formation at date 1, we now go back to date 0 and analyze the choice made by S-traders on whether to pay the $\operatorname{cost} \tau$ and become informed or not. An argument similar to that of Grossman and Stiglitz 1980) shows that for a given fraction $\mu$ of S-traders that choose to purchase the signal $\tilde{\theta}$, the expected net benefit from purchasing information to a potential purchaser is:

$$
\pi(\mu)=\sqrt{\frac{V A R\left(\tilde{v}_{A} \mid \tilde{p}_{A}, \tilde{p}_{B}\right)}{\sigma_{\varepsilon A}^{2}}}-e^{\gamma \tau} .
$$

That is, the trader benefits more from acquiring information when the variance of the asset's cash flow conditional on the information in the price system $\left(\operatorname{VAR}\left(\tilde{v}_{A} \mid \tilde{p}_{A}, \tilde{p}_{B}\right)\right)$ is significant relative to the variance conditional on knowing the fundamental $\tilde{\theta}\left(V A R\left(\tilde{v}_{A} \mid \tilde{\theta}, \tilde{p}_{A}, \tilde{p}_{B}\right)=\sigma_{\varepsilon A}^{2}\right)$.

Recall that prices $\tilde{p}_{A}$ and $\tilde{p}_{B}$ are functions of the size $\mu$ of informed S-traders, and hence the benefit $\pi$ of purchasing information is a function of $\mu$. Analyzing the benefit function $\pi(\cdot)$ enables us to determine the equilibrium fraction of informed S-traders, $\mu^{*}$. If $\pi(0)<0$ (i.e., a potential buyer does not benefit from becoming informed when no S-traders are informed), then there exists an equilibrium in the information market with $\mu^{*}=0$ (i.e., where no one purchases information). If $\pi(1)>0$, a potential buyer is strictly better off by being informed when all other S-traders are also informed. Then, there is an equilibrium where all S-traders are informed-that is, $\mu^{*}=1$. For an interior fraction of informed S-traders $\left(0<\mu^{*}<1\right)$, if every potential buyer is indifferent between becoming informed and remaining uninformed, i.e., $\pi\left(\mu^{*}\right)=0$, then that fraction $\mu^{*}$ represents an equilibrium fraction of informed S-traders.

Our focus here is on a particular feature of the benefit function $\pi(\cdot)$. We are interested in its shape, which determines whether information acquisition is a strategic complement or substitute. As we show later, this has implications for equilibrium multiplicity and the potential for price jumps. If $\pi(\cdot)$ is increasing (decreasing) at $\mu \geq 0$, then information acquisition is a strategic complement (substitute) at that fraction $\mu$. Under strategic complementarity (substitutability), S-traders' incentive to acquire information increases (decreases) in the fraction of informed S-traders. Formally, we have the following definition: 
Definition 1. [Strategic complement/substitute in information acquisition] If $\pi^{\prime}(\mu)>0$, then learning is a strategic complement at $\mu$, and if $\pi^{\prime}(\mu)<0$, then learning is a strategic substitute at $\mu$.

The traditional Grossman-Stiglitz framework exhibits strategic substitutes in information acquisition, as an increase in the proportion of traders who become informed implies that the price becomes more informative, and so the incentive to produce information, for traders who observe the price, decreases. As we will show, our model with segmented markets may generate an opposite force that gives rise to strategic complementarities in information acquisition. This has important implications, as strategic complementarities lead to multiple equilibria, which are sometimes interpreted as a source of instability in financial markets.

By Equation 30, we know that

$$
\pi^{\prime}(\mu)>0 \text { iff } \frac{\partial V A R\left(\tilde{v}_{A} \mid \tilde{p}_{A}, \tilde{p}_{B}\right)}{\partial \mu}>0 .
$$

Given the definition of $V A R\left(\tilde{v}_{A} \mid \tilde{p}_{A}, \tilde{p}_{B}\right)$,

$$
V A R\left(\tilde{v}_{A} \mid \tilde{p}_{A}, \tilde{p}_{B}\right)=V A R\left(\tilde{\theta} \mid \tilde{p}_{A}, \tilde{p}_{B}\right)+\sigma_{\varepsilon A}^{2},
$$

and the price-informativeness $I$,

$$
I=\frac{V A R(\tilde{\theta})}{V A R\left(\tilde{\theta} \mid \tilde{p}_{A}, \tilde{p}_{B}\right)}-1,
$$

we know that

$$
\frac{\partial V A R\left(\tilde{v}_{A} \mid \tilde{p}_{A}, \tilde{p}_{B}\right)}{\partial \mu}>0 \text { iff } \frac{\partial I}{\partial \mu}<0 .
$$

That is, the condition for strategic complementarities in information acquisition is that an increase in the fraction of informed S-traders makes the price system less informative, thereby increasing the incentive of the uninformed S-traders to become informed. The following proposition uses this observation to derive the ranges of parameters for which our model exhibits strategic complementarities versus substitutes.

Proposition 5. Let $\Delta \equiv \frac{\lambda\left(\phi \rho \sigma_{\varepsilon A} \sigma_{\varepsilon B}^{-1}-1\right)}{1-\rho^{2}}$.

(i) If $\left(\phi \rho \sigma_{\varepsilon A} \sigma_{\varepsilon B}^{-1}\right)>1$ (i.e., if $\left.\Delta>0\right)$, then information acquisition exhibits strategic complementarity for $\mu \in[0, \min \{\Delta, 1\}]$ and strategic substitute for $\mu \in[\min \{\Delta, 1\}, 1]$.

(ii) If $\left(\phi \rho \sigma_{\varepsilon A} \sigma_{\varepsilon B}^{-1}\right) \leq 1$ (i.e., if $\left.\Delta \leq 0\right)$, then information acquisition exhibits strategic substitute for $\mu \in[0,1]$.

The intuition is as follows. In response to information $\tilde{\theta}$, informed S-traders trade the A-asset for speculative reasons. At the same time, L-traders trade 
it both for hedging and for speculative reasons. When $\left(\phi \rho \sigma_{\varepsilon A} \sigma_{\varepsilon B}^{-1}\right)>1$, their trading of the A-asset is mainly for hedging reasons, and hence in this case, the trades of the informed S-traders respond to $\tilde{\theta}$ in opposite direction to those of the L-traders. Then, as long as the mass of informed S-traders is not very large (i.e., below $\Delta$ ), the informativeness of the price is driven by the trades of the L-traders, and adding more informed S-traders, who trade in the opposite direction, reduces the informativeness. This leads to the complementarity in information acquisition, as having more informed S-traders increases the incentive of other S-traders to become informed.

Note that this intuition is identical to the intuition behind Propositions 2 and 4 There, our focus is on price informativeness and asset prices due to the fact that both types of informed traders respond to $\tilde{\theta}$ in opposite directions. The additional implication here is that this leads to complementarities in information acquisition, as then uninformed S-traders find it more beneficial to acquire information.

Interestingly, the proposition provides implications as to when complementarities are more likely to arise. This is the case when the sensitivity of the B-asset to information $(\phi)$ is higher and when the mass of L-traders $(\lambda)$ is higher. Hence, take the example of the futures commodity market: complementarities among financial institutions in acquiring information before trading the futures contracts will arise when there are more commodities producers who participate in the futures market for hedging reasons.

\subsection{Multiplicity and price jumps}

We now explore the implications of learning complementarities for equilibrium outcomes in the information market. The following proposition characterizes equilibrium outcomes and reveals that a necessary condition for multiple equilibria in our model is the presence of learning complementarities.

Proposition 6. If $\pi(0)<0$ and $\max _{\mu \in[0,1]} \pi(\mu)>0$, or equivalently, if $\left(\lambda, \gamma, \tau, \rho, \phi, \sigma_{\theta}, \sigma_{\varepsilon A}, \sigma_{\varepsilon B}, \sigma_{n A}, \sigma_{n B}\right) \in \mathcal{R}_{\text {multiplicity }}$, where $\mathcal{R}_{\text {multiplicity }}$ is given by Equation $\mathrm{A5}$ in the Appendix, then there will be three equilibria in the information market: $\mu^{*}=0, \mu^{*}=\mu_{1}$, and $\mu^{*}=\mu_{2}$, where $\mu_{1}, \mu_{2} \in(0,1], \mu_{1}<\mu_{2}$, and only $\mu^{*}=0$ and $\mu^{*}=\mu_{2}$ are stable equilibria. Otherwise, there is a unique (stable) equilibrium.

As the proposition shows, for multiple equilibria to arise, the net benefit from information acquisition must be negative at $\mu=0$ and positive at some $\mu>0$. Hence, there must be a region where the net benefit from information production is increasing in the mass $\mu$ of S-traders who choose to acquire informationthat is, where strategic complementarities exist. We know from Proposition 5 that this happens only when $\left(\phi \rho \sigma_{\varepsilon A} \sigma_{\varepsilon B}^{-1}\right)>1$. Note that the condition of $\pi(0)<0$ for multiplicity in Proposition 6 indicates that when there are multiple information market equilibria, $\mu^{*}=0$ is always one of them. Moreover, it is a stable equilibrium. The other stable equilibrium can be either an interior 


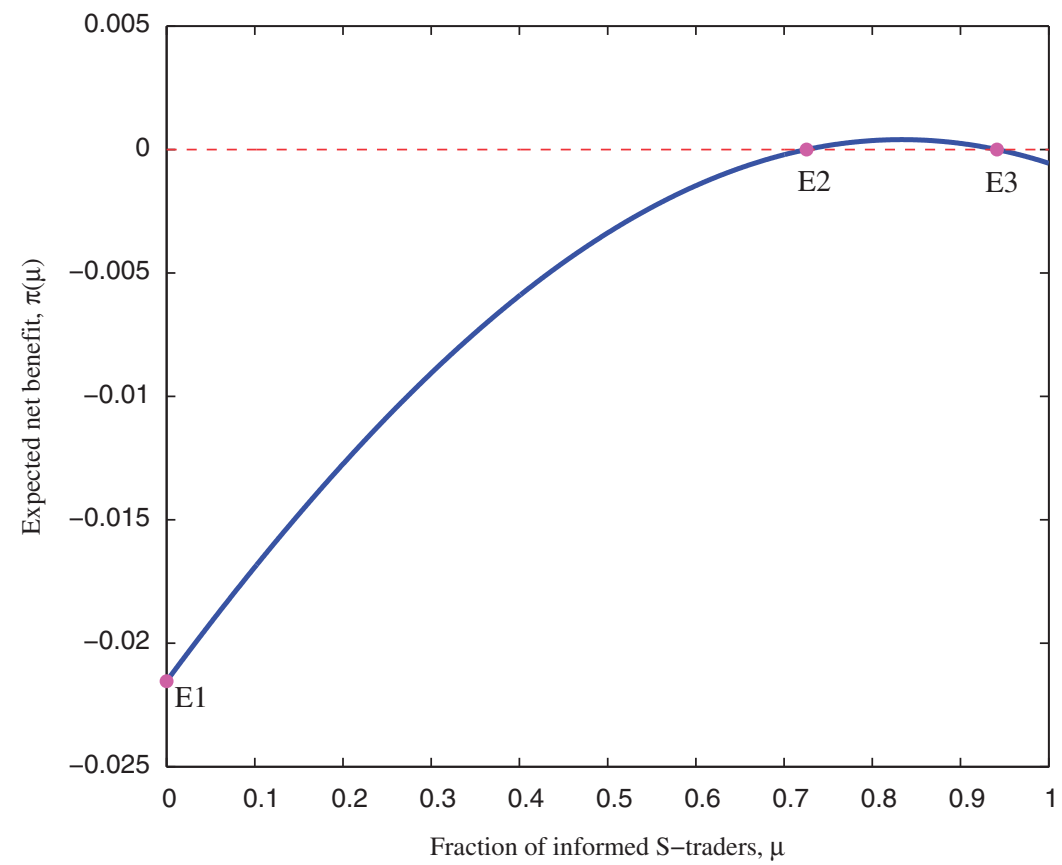

Figure 1

Learning complementarities and multiple equilibria

This figure shows the possibility of strategic complementarities in information acquisition and the resulting multiple equilibria in information market. Under the parameter configuration of $\gamma=2, \lambda=0.5, \rho=0.8, \phi=2$, $\tau=0.1158$, and $\sigma_{\theta}=\sigma_{\varepsilon A}=\sigma_{\varepsilon B}=\sigma_{n A}=\sigma_{n B}=1$, there are three equilibrium fractions of informed speculators: $\mu^{*} \in\{0,0.73,0.94\}$.

equilibrium (as Figure 1 illustrates) or $\mu^{*}=1$. In addition, there is another equilibrium where $\mu^{*}>0$, which is not stable.

Figure 1 illustrates the possibility of multiple equilibria in the information market in the model. The parameter values are set as $\gamma=2, \lambda=0.5, \rho=0.8$, $\phi=2, \tau=0.1158, \bar{x}_{A}=\bar{x}_{B}=1$, and $\sigma_{\theta}=\sigma_{\varepsilon A}=\sigma_{\varepsilon B}=\sigma_{n A}=\sigma_{n B}=1$. There are three information equilibria, where the corresponding equilibrium fractions of informed S-traders are $\mu^{*}=0,0.73$, and 0.94. Among these equilibria, the boundary equilibrium $\left(\mu^{*}=0\right)$ and the larger interior equilibrium $\left(\mu^{*}=0.94\right)$ are stable, while the other interior equilibrium $\left(\mu^{*}=0.73\right)$ is unstable.

The literature (e.g., Barlevy and Verones 2000; Garcia and Strob] 2011; Mele and Sangiorgi 2011) has used learning complementarities and the resulting multiple equilibria to explain large movements in stock prices and excess volatility in financial markets. The same is true in our model. Importantly, this does not depend on unexplained shifts across equilibria when different equilibria are possible. Rather, independent of which (stable) equilibrium traders coordinate on, an infinitesimal shift in exogenous parameters can always 

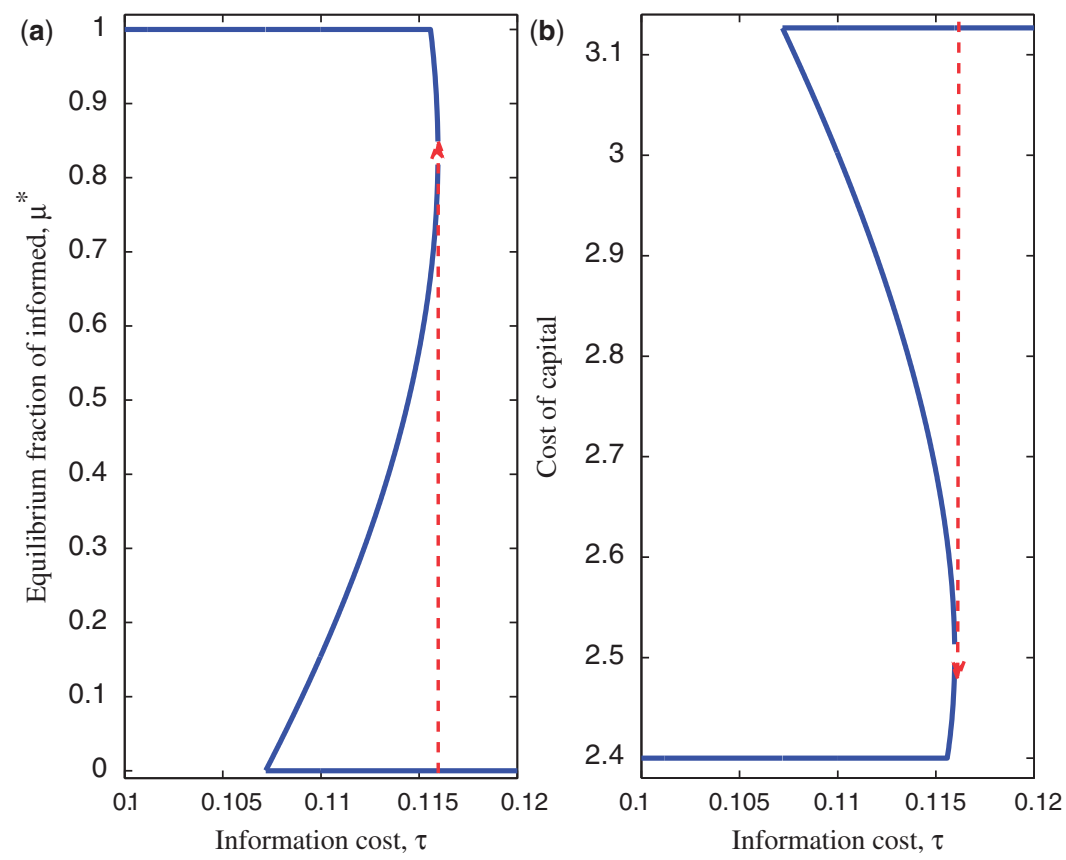

Figure 2

Multiplicity and price jumps

This figure shows the implications of changing the information cost $\tau$ for the information market equilibrium and the cost of capital. The parameters take values: $\gamma=2, \lambda=0.5, \rho=0.8, \phi=2, \bar{x}_{A}=\bar{x}_{B}=1$, and $\sigma_{\theta}=\sigma_{\varepsilon A}=\sigma_{\varepsilon B}=$ $\sigma_{n A}=\sigma_{n B}=1$.

make traders switch between no-information and high-information equilibria, thereby leading to a discrete jump in asset prices 20 We illustrate this idea in Figure 2 by examining the effect of changes in the information acquisition $\operatorname{cost} \tau 21$

In Figure 2 we consider the same parameter values as in Figure 1 except that we consider a range of values for the information acquisition $\cos t \tau$. The left panel of the figure depicts the equilibrium fractions of informed S-traders $\mu^{*}$ against the information acquisition $\operatorname{cost} \tau$, while the right panel depicts the cost of capital $E\left(\tilde{v}_{A}-\tilde{p}_{A}\right)$ against $\tau$. The cost of information $\tau$ represents a measure of the easiness of collecting information: a proliferation of sources of information about financial markets leads to easier access to information and corresponds to a low value of $\tau$. As $\tau$ falls to slightly below 0.116 , the number of information market equilibria jumps from $1\left(\mu^{*}=0\right)$ to $3\left(\mu^{*}=0\right.$ or

20 In mathematical terms, this means that the derivatives of the equilibrium fraction $\mu^{*}$ of informed S-traders and the equilibrium price $E\left(\tilde{p}_{A}\right)$ with respect to some exogenous parameters can take values of infinity.

21 The same idea can be illustrated by examining the effect of changes in other parameters. The results are robust to the choice of parameter values, as long as $\left(\phi \rho \sigma_{\varepsilon A} \sigma_{\varepsilon B}^{-1}\right)>1$. 
$\left.\mu^{*} \in(0,1]\right)$ in Figure 2 a), and as $\tau$ continues to fall close to 0.107 , the number of information market equilibria jumps down from $3\left(\mu^{*}=0\right.$ or $\left.\mu^{*} \in(0,1]\right)$ to $1\left(\mu^{*}=1\right)$. So, no matter what equilibrium traders coordinate on, it is clear that changes in $\tau$ will inevitably induce discrete price jumps, as $\tau$ goes through the range of $[0.107,0.116]$. For example, suppose that, out of the set of possible equilibria, the information market always coordinates on the equilibrium with the largest fraction of informed traders, then as the information cost $\tau$ drops slightly below 0.116 , there will be a jump in information acquisition from $\mu^{*}=0$ to $\mu^{*}=0.85$ in Figure 2 a), and accordingly, there will be a sharp drop in the cost of capital from 3.13 to 2.49 in Figure 2 b). In addition, as a result of this jump, stock prices exhibit more volatility than do the underlying fundamentals, leading to excess volatility.

\section{Conclusion}

We analyze a model where traders have heterogenous investment opportunities and learn information from observing prices. L-traders have a large investment opportunity set by trading two risky assets, while S-traders have access only to one risky asset. The presence of L-traders with an additional investment vehicle in this segmented setting may have adverse implications for price informativeness. The key intuition is that L-traders have different trading motives in the commonly traded risky asset than S-traders, since they sometimes use it for hedging purposes. The diversity of trading motives may reduce the informativeness of the price and increase the cost of capital. This may also lead to complementarities in information production, as having more S-traders trade against the L-traders reduces the informativeness of the price, and induces more traders to produce information.

Our model captures a key feature of modern financial markets-namely, that capital is relatively segmented and slow moving, but information is relatively integrated and fast moving, and traders actively use this information. This notion of segmentation/integration is very relevant for today's markets given the improvement of information technology on the one hand and the specialization and delegation of investment on the other hand, making it easy for information to flow across markets but putting frictions on the flow of capital. Our analysis provides implications for policy debates and empirical work. In particular, it is useful for understanding the determinants of the futures risk premium and the optimal scope of hedge fund activities.

\section{Appendix A. Proofs}

\section{Proof of Proposition 1}

Using Equations 9 and 15, we have:

$$
\frac{\rho\left(\phi \tilde{\theta}-\tilde{p}_{B}\right)}{\gamma\left(1-\rho^{2}\right) \sigma_{\varepsilon A} \sigma_{\varepsilon B}}=\frac{\rho\left(\bar{x}_{B}-\tilde{n}_{B}\right) \sigma_{\varepsilon B}}{\lambda \sigma_{\varepsilon A}}+\frac{\rho^{2}\left(\tilde{\theta}-\tilde{p}_{A}\right)}{\gamma\left(1-\rho^{2}\right) \sigma_{\varepsilon A}^{2}} .
$$


Inserting the above expression into the L-traders' demand for the A-asset (Equation 8), we have

$$
D_{A}^{L}\left(\tilde{\theta}, \tilde{p}_{A}, \tilde{p}_{B}\right)=\frac{\tilde{\theta}-\tilde{p}_{A}}{\gamma\left(1-\rho^{2}\right) \sigma_{\varepsilon A}^{2}}-\frac{\rho\left(\phi \tilde{\theta}-\tilde{p}_{B}\right)}{\gamma\left(1-\rho^{2}\right) \sigma_{\varepsilon A} \sigma_{\varepsilon B}}=\frac{\tilde{\theta}-\tilde{p}_{A}}{\gamma \sigma_{\varepsilon A}^{2}}-\frac{\rho\left(\bar{x}_{B}-\tilde{n}_{B}\right) \sigma_{\varepsilon B}}{\lambda \sigma_{\varepsilon A}} .
$$

Plugging the above expression of $D_{A}^{L}$, the expression of $D_{A}^{I}$ in Equation 12, and the expression of $D_{A}^{U}$ in Equation [14, into the market-clearing condition of the A-asset in Equation 18], we can solve for the price $\tilde{p}_{A}$ as follows:

$$
\begin{aligned}
& {\left[\frac{\lambda+\mu}{\gamma \sigma_{\varepsilon A}^{2}}+\frac{1-\mu}{\gamma V A R\left(\tilde{v}_{A} \mid \tilde{p}_{A}, \tilde{p}_{B}\right)}\right] \tilde{p}_{A}} \\
& =\left(-\bar{x}_{A}-\frac{\rho \sigma_{\varepsilon B}}{\sigma_{\varepsilon A}} \bar{x}_{B}\right)+\left[\frac{\lambda+\mu}{\gamma \sigma_{\varepsilon A}^{2}}+\frac{(1-\mu) V A R\left(\tilde{\theta} \mid \tilde{s}_{A}, \tilde{s}_{B}\right)}{\gamma V A R\left(\tilde{v}_{A} \mid \tilde{p}_{A}, \tilde{p}_{B}\right)}\left(k_{A}^{2} \sigma_{n A}^{-2}+k_{B}^{2} \sigma_{n B}^{-2}\right)\right] \tilde{\theta} \\
& +\left[\frac{(1-\mu) V A R\left(\tilde{\theta} \mid \tilde{s}_{A}, \tilde{s}_{B}\right)}{\gamma V A R\left(\tilde{v}_{A} \mid \tilde{p}_{A}, \tilde{p}_{B}\right)} k_{A} \sigma_{n A}^{-2}+1\right] \tilde{n}_{A}+\left[\frac{(1-\mu) V A R\left(\tilde{\theta} \mid \tilde{s}_{A}, \tilde{s}_{B}\right)}{\gamma V A R\left(\tilde{v}_{A} \mid \tilde{p}_{A}, \tilde{p}_{B}\right)} k_{B} \sigma_{n B}^{-2}+\frac{\rho \sigma_{\varepsilon B}}{\sigma_{\varepsilon A}}\right] \tilde{n}_{B} .
\end{aligned}
$$

Then, substituting the expression of $\tilde{p}_{A}$ into Equation A1, we can solve for the expression of $\tilde{p}_{B}$. With a bit more algebra, we get the following coefficients for the price equations in the body of the proposition:

$$
\begin{aligned}
& a_{0}=-\frac{\bar{x}_{A}+\left(\rho \sigma_{\varepsilon A}^{-1} \sigma_{\varepsilon B}\right) \bar{x}_{B}}{\Omega}, a_{\theta}=\frac{1}{\Omega}\left[\frac{\lambda+\mu}{\gamma \sigma_{\varepsilon A}^{2}}+\frac{(1-\mu) V A R\left(\tilde{\theta} \mid \tilde{s}_{A}, \tilde{s}_{B}\right)}{\gamma V A R\left(\tilde{v}_{A} \mid \tilde{p}_{A}, \tilde{p}_{B}\right)}\left(k_{A}^{2} \sigma_{n A}^{-2}+k_{B}^{2} \sigma_{n B}^{-2}\right)\right], \\
& a_{A}=\frac{1}{\Omega}\left[\frac{(1-\mu) V A R\left(\tilde{\theta} \mid \tilde{s}_{A}, \tilde{s}_{B}\right)}{\gamma V A R\left(\tilde{v}_{A} \mid \tilde{p}_{A}, \tilde{p}_{B}\right)} k_{A} \sigma_{n A}^{-2}+1\right], a_{B}=\frac{1}{\Omega}\left[\frac{(1-\mu) V A R\left(\tilde{\theta} \mid \tilde{s}_{A}, \tilde{s}_{B}\right)}{\gamma V A R\left(\tilde{v}_{A} \mid \tilde{p}_{A}, \tilde{p}_{B}\right)} k_{B} \sigma_{n B}^{-2}+\frac{\rho \sigma_{\varepsilon B}}{\sigma_{\varepsilon A}}\right], \\
& b_{0}=\rho \sigma_{\varepsilon A}^{-1} \sigma_{\varepsilon B} a_{0}-\gamma \lambda^{-1}\left(1-\rho^{2}\right) \sigma_{\varepsilon B}^{2} \bar{x}_{B}, b_{\theta}=\phi+\rho \sigma_{\varepsilon A}^{-1} \sigma_{\varepsilon B}\left(a_{\theta}-1\right), \\
& b_{A}=\rho \sigma_{\varepsilon A}^{-1} \sigma_{\varepsilon B} a_{A}, b_{B}=\rho \sigma_{\varepsilon A}^{-1} \sigma_{\varepsilon B} a_{B}+\gamma \lambda^{-1}\left(1-\rho^{2}\right) \sigma_{\varepsilon B}^{2}, \\
& \text { with } \quad k_{A}=\frac{\lambda\left(1-\phi \rho \sigma_{\varepsilon A} \sigma_{\varepsilon B}^{-1}\right)}{\gamma\left(1-\rho^{2}\right) \sigma_{\varepsilon A}^{2}}+\frac{\mu}{\gamma \sigma_{\varepsilon A}^{2}}, \quad k_{B}=\frac{\lambda\left(\phi \sigma_{\varepsilon B}^{-1}-\rho \sigma_{\varepsilon A}^{-1}\right)}{\gamma\left(1-\rho^{2}\right) \sigma_{\varepsilon B}}, \quad \Omega=\frac{\lambda+\mu}{\gamma \sigma_{\varepsilon A}^{2}}+\frac{1-\mu}{\gamma V A R\left(\tilde{v}_{A} \mid \tilde{p}_{A}, \tilde{p}_{B}\right)} \quad \text { and } \\
& V A R\left(\tilde{v}_{A} \mid \tilde{p}_{A}, \tilde{p}_{B}\right)=\left(\sigma_{\theta}^{-2}+k_{A}^{2} \sigma_{n A}^{-2}+k_{B}^{2} \sigma_{n B}^{-2}\right)^{-1}+\sigma_{\varepsilon A}^{2} . \quad \|
\end{aligned}
$$

\section{Proof of Proposition2}

(i) We know from 23] that $\frac{\partial I}{\partial \lambda}=\frac{\partial k_{A}^{2}}{\partial \lambda} \frac{\sigma_{\theta}^{2}}{\sigma_{n A}^{2}}+\frac{\partial k_{B}^{2}}{\partial \lambda} \frac{\sigma_{\theta}^{2}}{\sigma_{n B}^{2}}$. Then, given the definitions of $k_{A}^{2}$ and $k_{B}^{2}$ in 177) and 19, we get:

$$
\begin{aligned}
\frac{\partial I}{\partial \lambda} & =2 k_{A} \frac{\sigma_{\theta}^{2}}{\sigma_{n A}^{2}} \frac{\partial k_{A}}{\partial \lambda}+2 k_{B} \frac{\sigma_{\theta}^{2}}{\sigma_{n B}^{2}} \frac{\partial k_{B}}{\partial \lambda} \\
& =2 \lambda\left[\frac{1-\phi \rho \sigma_{\varepsilon A} \sigma_{\varepsilon B}^{-1}}{\gamma\left(1-\rho^{2}\right) \sigma_{\varepsilon A}^{2}}\right]^{2} \frac{\sigma_{\theta}^{2}}{\sigma_{n A}^{2}}+2 \lambda\left[\frac{\phi \sigma_{\varepsilon B}^{-1}-\rho \sigma_{\varepsilon A}^{-1}}{\gamma\left(1-\rho^{2}\right) \sigma_{\varepsilon B}}\right]^{2} \frac{\sigma_{\theta}^{2}}{\sigma_{n B}^{2}}+\frac{2 \mu}{\gamma \sigma_{\varepsilon A}^{2}} \frac{\sigma_{\theta}^{2}}{\sigma_{n A}^{2}} \frac{\left(1-\phi \rho \sigma_{\varepsilon A} \sigma_{\varepsilon B}^{-1}\right)}{\gamma\left(1-\rho^{2}\right) \sigma_{\varepsilon A}^{2}} .
\end{aligned}
$$

Thus, $\frac{\partial I}{\partial \lambda}<0$ if and only if

$$
\lambda\left[1+\left(\frac{\left(\phi \sigma_{\varepsilon B}^{-1}-\rho \sigma_{\varepsilon A}^{-1}\right) \sigma_{\varepsilon A}^{2}}{\left(1-\phi \rho \sigma_{\varepsilon A} \sigma_{\varepsilon B}^{-1}\right) \sigma_{\varepsilon B}}\right)^{2} \frac{\sigma_{n A}^{2}}{\sigma_{n B}^{2}}\right]<\frac{\mu\left(1-\rho^{2}\right)}{\phi \rho \sigma_{\varepsilon A} \sigma_{\varepsilon B}^{-1}-1},
$$

which requires that $\left(\phi \rho \sigma_{\varepsilon A} \sigma_{\varepsilon B}^{-1}\right)>1$ and $\lambda$ is small. 
(ii) Note that $I$ depends on $\mu$ only through $k_{A}$. Hence, $\frac{\partial I}{\partial \mu}=\frac{\partial k_{A}^{2}}{\partial \mu} \frac{\sigma_{\theta}^{2}}{\sigma_{n A}^{2}}=2 k_{A} \frac{1}{\gamma \sigma_{\varepsilon A}^{2}} \frac{\sigma_{\theta}^{2}}{\sigma_{n A}^{2}}$ and therefore, $\frac{\partial I}{\partial \mu}<0 \Leftrightarrow k_{A}<0$. We can show that

$$
k_{A}=\frac{\lambda\left(1-\phi \rho \sigma_{\varepsilon A} \sigma_{\varepsilon B}^{-1}\right)}{\gamma\left(1-\rho^{2}\right) \sigma_{\varepsilon A}^{2}}+\frac{\mu}{\gamma \sigma_{\varepsilon A}^{2}}<0 \Leftrightarrow \mu<\frac{\lambda\left(\phi \rho \sigma_{\varepsilon A} \sigma_{\varepsilon B}^{-1}-1\right)}{1-\rho^{2}} .
$$

Then, the result follows. $\|$

\section{Proof of Proposition 3}

We know from 23 that:

$$
\begin{aligned}
\frac{\partial I}{\partial \phi} & =\frac{\partial k_{A}^{2}}{\partial \phi} \frac{\sigma_{\theta}^{2}}{\sigma_{n A}^{2}}+\frac{\partial k_{B}^{2}}{\partial \phi} \frac{\sigma_{\theta}^{2}}{\sigma_{n B}^{2}}=2 k_{A} \frac{-\lambda \rho \sigma_{\varepsilon A} \sigma_{\varepsilon B}^{-1}}{\gamma\left(1-\rho^{2}\right) \sigma_{\varepsilon A}^{2}} \frac{\sigma_{\theta}^{2}}{\sigma_{n A}^{2}}+2 k_{B} \frac{\lambda \sigma_{\varepsilon B}^{-1}}{\gamma\left(1-\rho^{2}\right) \sigma_{\varepsilon B}} \frac{\sigma_{\theta}^{2}}{\sigma_{n B}^{2}} \\
& =\frac{2 \sigma_{\theta}^{2} \lambda \sigma_{\varepsilon B}^{-1}}{\gamma^{2}\left(1-\rho^{2}\right)}\left[\frac{\lambda\left(\phi \sigma_{\varepsilon B}^{-1}-\rho \sigma_{\varepsilon A}^{-1}\right)}{\left(1-\rho^{2}\right) \sigma_{\varepsilon B}^{2} \sigma_{n B}^{2}}-\left(\frac{\lambda\left(1-\phi \rho \sigma_{\varepsilon A} \sigma_{\varepsilon B}^{-1}\right)}{1-\rho^{2}}+\mu\right) \frac{\rho}{\sigma_{\varepsilon A}^{3} \sigma_{n A}^{2}}\right] .
\end{aligned}
$$

For $\phi$ sufficiently small, the term $\left(\phi \sigma_{\varepsilon B}^{-1}-\rho \sigma_{\varepsilon A}^{-1}\right)$ is negative, which reflects the fact that L-traders use the B-asset primarily for hedging, and the term $\left(1-\phi \rho \sigma_{\varepsilon A} \sigma_{\varepsilon B}^{-1}\right)$ is positive, which reflects the fact that L-traders use the A-asset primarily for speculation; so, it follows that $\frac{\partial I}{\partial \phi}<0$. Similarly, $\frac{\partial I}{\partial \phi}>0$ for $\phi$ sufficiently large. \|

\section{Proof of Proposition 4}

(i) We take derivative of $\Omega$ with respect to $\lambda$ at $\lambda=0$ :

$$
\begin{aligned}
\left.\frac{\partial \Omega}{\partial \lambda}\right|_{\lambda=0} & =\frac{1}{\gamma \sigma_{\varepsilon A}^{2}}+\frac{1-\mu}{\gamma} \frac{\left(\sigma_{\theta}^{-2}+k_{A}^{2} \sigma_{n A}^{-2}+k_{B}^{2} \sigma_{n B}^{-2}\right)^{-2}}{V A R^{2}\left(\tilde{v}_{A} \mid \tilde{p}_{A}, \tilde{p}_{B}\right)} \frac{2 \mu \sigma_{n A}^{-2}}{\gamma \sigma_{\varepsilon A}^{2}} \frac{\left(1-\phi \rho \sigma_{\varepsilon A} \sigma_{\varepsilon B}^{-1}\right)}{\gamma\left(1-\rho^{2}\right) \sigma_{\varepsilon A}^{2}} \\
& =\frac{1}{\gamma \sigma_{\varepsilon A}^{2}}+\frac{2 \mu(1-\mu) \sigma_{n A}^{-2}\left(1-\phi \rho \sigma_{\varepsilon A} \sigma_{\varepsilon B}^{-1}\right)}{\gamma^{3} \sigma_{\varepsilon A}^{4}\left(1-\rho^{2}\right)\left[1+\left(\sigma_{\theta}^{-2}+\left(\mu \gamma^{-1} \sigma_{\varepsilon A}^{-2}\right)^{2} \sigma_{n A}^{-2}\right) \sigma_{\varepsilon A}^{2}\right]^{2}} .
\end{aligned}
$$

It is clear that the above expression is negative when either $\phi$ is large enough or $\sigma_{\varepsilon B}$ is small enough. Hence, in this case, and when $\lambda$ is sufficiently small, $\frac{\partial C C}{\partial \lambda}>0$.

Now suppose that $\lambda$ is large. By part (ii) of Proposition $2 \frac{\partial I}{\partial \lambda}>0$. Given

$$
\Omega=\frac{\lambda+\mu}{\gamma \sigma_{\varepsilon A}^{2}}+\frac{1-\mu}{\gamma V A R\left(\tilde{v}_{A} \mid \tilde{p}_{A}, \tilde{p}_{B}\right)}=\frac{\lambda+\mu}{\gamma \sigma_{\varepsilon A}^{2}}+\frac{1-\mu}{\gamma\left(\frac{\sigma_{\theta}^{2}}{I+1}+\sigma_{\varepsilon A}^{2}\right)},
$$

we have $\frac{\partial \Omega}{\partial \lambda}>0$ since both $\frac{\lambda+\mu}{\gamma \sigma_{\varepsilon A}^{2}}$ and $\frac{1-\mu}{\gamma\left(\frac{\sigma_{\theta}^{2}}{I+1}+\sigma_{\varepsilon A}^{2}\right)}$ increase with $\lambda$. Thus, $\frac{\partial C C}{\partial \lambda}<0$ for large $\lambda$.

(ii) Direct computation shows:

$$
\frac{\partial \Omega}{\partial \mu}=\left[\frac{1}{\gamma \sigma_{\varepsilon A}^{2}}-\frac{1}{\gamma V A R\left(\tilde{v}_{A} \mid \tilde{p}_{A}, \tilde{p}_{B}\right)}\right]+k_{A} \frac{2(1-\mu)}{\gamma^{2} \sigma_{\varepsilon A}^{2} \sigma_{n A}^{2}} \frac{\left(\sigma_{\theta}^{-2}+k_{A}^{2} \sigma_{n A}^{-2}+k_{B}^{2} \sigma_{n B}^{-2}\right)^{-2}}{V A R^{2}\left(\tilde{v}_{A} \mid \tilde{p}_{A}, \tilde{p}_{B}\right)} .
$$

Note that $\left[\frac{1}{\gamma \sigma_{\varepsilon A}^{2}}-\frac{1}{\gamma V A R\left(\tilde{v}_{A} \mid \tilde{p}_{A}, \tilde{p}_{B}\right)}\right]>0$. So, if $k_{A} \geq 0$ - that is, if $k_{A} \geq 0 \Leftrightarrow \mu \geq \frac{\lambda\left(\phi \rho \sigma_{\varepsilon A} \sigma_{\varepsilon B}^{-1}-1\right)}{1-\rho^{2}}-$ then we will have $\frac{\partial \Omega}{\partial \mu}>0$, and hence $\frac{\partial C C}{\partial \mu}<0$. 
If $k_{A}<0$ - that is, if $\mu<\frac{\lambda\left(\phi \rho \sigma_{\left.\varepsilon A^{\sigma} \sigma_{\varepsilon B}^{-1}-1\right)}\right.}{1-\rho^{2}}$ and if in addition, as $\phi \rightarrow \infty$ so that $\quad k_{A}=\frac{\lambda\left(1-\phi \rho \sigma_{\varepsilon A} \sigma_{\varepsilon B}^{-1}\right)}{\gamma\left(1-\rho^{2}\right) \sigma_{\varepsilon A}^{2}}+\frac{\mu}{\gamma \sigma_{\varepsilon A}^{2}} \rightarrow-\infty, \quad$ then $\quad\left[\frac{1}{\gamma \sigma_{\varepsilon A}^{2}}-\frac{1}{\gamma V A R\left(\tilde{v}_{A} \mid \tilde{p}_{A}, \tilde{p}_{B}\right)}\right] \rightarrow 0 \quad$ and $k_{A} \frac{2(1-\mu)}{\gamma^{2} \sigma_{\varepsilon A}^{2} \sigma_{n A}^{2}} \frac{\left(\sigma_{\theta}^{-2}+k_{A}^{2} \sigma_{n A}^{-2}+k_{B}^{2} \sigma_{n B}^{-2}\right)^{-2}}{V A R^{2}\left(\tilde{v}_{A} \mid \tilde{p}_{A}, \tilde{p}_{B}\right)} \rightarrow-\infty$, implying that $\frac{\partial \Omega}{\partial \mu}<0$ and $\frac{\partial C C}{\partial \mu}>0 . \quad \|$

\section{Proof of Proposition 5}

The result stated in the proposition follows directly from part (ii) of Proposition $\_$॥

\section{Proof of Proposition 6}

When $\left(\phi \rho \sigma_{\varepsilon A} \sigma_{\varepsilon B}^{-1}\right) \leq 1$, function $\pi$ is decreasing in $\mu$ and there is a unique equilibrium in the information market. This is consistent with Proposition 6 the conditions $\pi(0)<0$ and $\max _{\mu \in[0,1]} \pi(\mu)>0$ can never be satisfied simultaneously, and as a result, uniqueness is guaranteed by the proposition.

Consider the case of $\left(\phi \rho \sigma_{\varepsilon A} \sigma_{\varepsilon B}^{-1}\right)>1$. In this case, Proposition 5 demonstrates that function $\pi$ first increases with $\mu$ and then decreases with $\mu$. We have the following three possibilities to discuss.

Suppose $\pi(0)<0$ and $\max _{\mu \in[0,1]} \pi(\mu)>0$. Then function $\pi$ crosses zero either once or twice in the range of $[0,1]$, depending on the sign of $\pi(1)$. If $\pi(1)<0$, then function $\pi$ crosses zero twice in the range of $[0,1]$, say, at the values of $\mu_{1} \in(0,1)$ and $\mu_{2} \in\left(\mu_{1}, 1\right)$, implying that there are three information market equilibria: $\mu^{*}=0, \mu_{1}$, and $\mu_{2}$. Among these three equilibria, 0 and $\mu_{2}$ are stable, while $\mu_{1}$ is unstable. If $\pi(1) \geq 0$, then function $\pi$ crosses zero once in the range of $[0,1]$, say, at the value of $\mu_{1} \in(0,1)$, and there are still three information market equilibria: $0, \mu_{1}$, and $1 . \mu^{*}=0$ and $\mu^{*}=1$ are stable equilibria, while the interior equilibrium $\mu_{1}$ is unstable.

Suppose $\pi(0)>0$. If, in addition, $\pi(1) \geq 0$, then $\pi(\mu)>0$ for all values of $\mu$ in the range of $(0,1)$, so that there is a unique information market equilibrium $\left(\mu^{*}=1\right)$ and it is stable. If $\pi(1)<0$, then $\pi$ crosses zero once in the range of $[0,1]$, and this value forms the unique equilibrium. (If $\pi(0)=0$, then besides the stable equilibrium in $(0,1], \mu^{*}=0$ is also an equilibrium, but it is unstable.)

Suppose $\max _{\mu \in[0,1]} \pi(\mu)<0$. Then the only equilibrium is $\mu^{*}=0$, and it is stable. (If $\max _{\mu \in[0,1]} \pi(\mu)=0$, then besides 0 , the value of $\mu$ that achieves the maximum is also an equilibrium, but again, it is unstable.)

Finally, we characterize the conditions on multiplicity in terms of exogenous parameters. By the definition of $\pi$ (Equation [30) and Equations 17, 19, 201 and 222, we can compute $\pi(\mu)=$ $\sqrt{\frac{1}{\left[\sigma_{\theta}^{-2}+\left(\lambda \delta_{A}^{L}+\mu \delta_{A}^{I}\right)^{2} \sigma_{n A}^{-2}+\left(\lambda \delta_{B}^{L}\right)^{2} \sigma_{n B}^{-2}\right] \sigma_{\varepsilon A}^{2}}+1}-e^{\gamma \tau}$. So, the condition of $\pi(0)<0$ is equivalent to:

$$
\sigma_{\theta}^{-2}+\lambda^{2}\left(\delta_{A}^{L}\right)^{2} \sigma_{n A}^{-2}+\lambda^{2}\left(\delta_{B}^{L}\right)^{2} \sigma_{n B}^{-2}>\frac{1}{\left(e^{2 \gamma \tau}-1\right) \sigma_{\varepsilon A}^{2}} .
$$

From the above discussions, we also know that $\max _{\mu \in[0,1]} \pi(\mu)>0$ requires $\left(\phi \rho \sigma_{\varepsilon A} \sigma_{\varepsilon B}^{-1}\right)>1$. Proposition 5 demonstrates $\pi(\mu)$ achieves maximum at $\mu=\min \{\Delta, 1\}$, and hence:

$$
\max _{\mu \in[0,1]} \pi(\mu)>0 \Rightarrow \sigma_{\theta}^{-2}+\left(\lambda \delta_{A}^{L}+\min \{\Delta, 1\} \delta_{A}^{I}\right)^{2} \sigma_{n A}^{-2}+\left(\lambda \delta_{B}^{L}\right)^{2} \sigma_{n B}^{-2}<\frac{1}{\left(e^{2 \gamma \tau}-1\right) \sigma_{\varepsilon A}^{2}} .
$$

Therefore, the parameters leading to multiplicity are completely characterized by conditions A3, A4, and $\left(\phi \rho \sigma_{\varepsilon A} \sigma_{\varepsilon B}^{-1}\right)>1$. Using $\delta_{A}^{L}=\frac{1-\phi \rho \sigma_{\varepsilon A} \sigma_{\varepsilon B}^{-1}}{\gamma\left(1-\rho^{2}\right) \sigma_{\varepsilon A}^{2}}, \delta_{B}^{L}=\frac{\phi-\rho \sigma_{\varepsilon A}^{-1} \sigma_{\varepsilon B}}{\gamma\left(1-\rho^{2}\right) \sigma_{\varepsilon B}^{2}}, \delta_{A}^{I}=\frac{1}{\gamma \sigma_{\varepsilon A}^{2}}$, and $\Delta=\frac{\lambda\left(\phi \rho \sigma_{\varepsilon A} \sigma_{\varepsilon B}^{-1}-1\right)}{1-\rho^{2}}$, we can express conditions and in terms of exogenous 
parameters. As a result, multiple equilibria exist in the information market if and only if $\left(\lambda, \gamma, \tau, \rho, \phi, \sigma_{\theta}, \sigma_{\varepsilon A}, \sigma_{\varepsilon B}, \sigma_{n A}, \sigma_{n B}\right) \in \mathcal{R}_{\text {multiplicity }}$, where

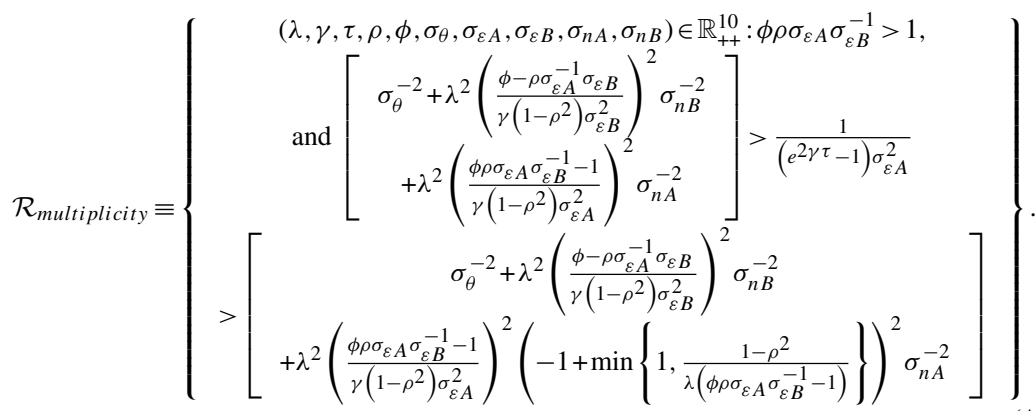

\section{Appendix B. Discussion of features of the model}

As we argued in the main text, the unique results of our model originate from the segmentation in trading opportunities that comes together with observability of prices across markets. We argued that this setup is empirically relevant in modern financial markets as capital is slow to move due to delegation and specialization, whereas price information is fast moving due to the technology and various data sources. In this Appendix, we demonstrate the importance of these two features of the model for our main results. We start with the role of segmentation in trading opportunities and continue with the role of price observability.

\section{B.1 The role of segmentation in trading opportunities}

Consider a model without market segmentation - that is, where both L-traders and S-traders can trade all assets. This is a version of the standard setting studied in the literature going back to Admati 1985). Analyzing such a model and comparing it with our model will enable us to get a clear understanding of the role that segmentation plays in our model and its results. We conduct this analysis in this subsection.

Since the L-traders and the informed S-traders can trade the two risky assets, they are essentially identical, and their demand functions for both assets are given by Equations 8 and 9 . We follow the same steps as in our main model and show that the prices imply the following two signals to uninformed traders:

$$
\begin{aligned}
& \tilde{\theta}+h_{A}^{-1} \tilde{n}_{A}, \text { with } h_{A}=(\lambda+\mu) \delta_{A}^{L}, \\
& \tilde{\theta}+h_{B}^{-1} \tilde{n}_{B}, \text { with } h_{B}=(\lambda+\mu) \delta_{B}^{L} .
\end{aligned}
$$

Then, the overall informativeness of the price system to uninformed traders is:

$$
I_{\text {No-Segmentation }}=\left(\frac{(\lambda+\mu)\left(1-\phi \rho \sigma_{\varepsilon A} \sigma_{\varepsilon B}^{-1}\right)}{\gamma\left(1-\rho^{2}\right) \sigma_{\varepsilon A}^{2}}\right)^{2} \frac{\sigma_{\theta}^{2}}{\sigma_{n A}^{2}}+\left(\frac{(\lambda+\mu)\left(\phi \sigma_{\varepsilon B}^{-1}-\rho \sigma_{\varepsilon A}^{-1}\right)}{\gamma\left(1-\rho^{2}\right) \sigma_{\varepsilon B}}\right)^{2} \frac{\sigma_{\theta}^{2}}{\sigma_{n B}^{2}} .
$$

The expression in B3 is unambiguously increasing in $\lambda$ and in $\mu$, and so an increase in the mass of informed traders in the model with no segmentation is always beneficial to informativeness. This also implies that the model with no segmentation does not generate strategic complementarities in information production. Hence, it is clear that the results of our model, which were presented and discussed in the main text, depend crucially on the presence of segmentation. Intuitively, 
when both types of agents can trade both assets, they will make similar choices as to the direction of trade in a given asset in response to information. Our results, where agents trade an asset in different directions in response to the same information, are driven by the differences in their trading opportunities.

\section{B.2 The role of price observability}

For our main results to hold, it is important that price information available to L-traders will also be available to S-traders. To see this, suppose that L-traders can still observe $\tilde{p}_{A}$ and $\tilde{p}_{B}$, while $\mathrm{S}$-traders can only observe $\tilde{p}_{A}$. Following the steps in our main model, we now derive the signal that uninformed S-traders extract from the price $\tilde{p}_{A}$. The market-clearing condition for the A-asset is:

$$
\lambda D_{A}^{L}\left(\tilde{\theta}, \tilde{p}_{A}, \tilde{p}_{B}\right)+\mu D_{A}^{I}\left(\tilde{\theta}, \tilde{p}_{A}\right)+\tilde{n}_{A}=\bar{x}_{A},
$$

where by Equations 8 and 12 ,

$$
D_{A}^{L}\left(\tilde{\theta}, \tilde{p}_{A}, \tilde{p}_{B}\right)=\frac{\tilde{\theta}-\tilde{p}_{A}}{\gamma\left(1-\rho^{2}\right) \sigma_{\varepsilon A}^{2}}-\frac{\rho\left(\phi \tilde{\theta}-\tilde{p}_{B}\right)}{\gamma\left(1-\rho^{2}\right) \sigma_{\varepsilon A} \sigma_{\varepsilon B}} \text { and } D_{A}^{I}\left(\tilde{\theta}, \tilde{p}_{A}\right)=\frac{\tilde{\theta}-\tilde{p}_{A}}{\gamma \sigma_{\varepsilon A}^{2}} \text {. }
$$

Now, using Equation (which is obtained from the market-clearing condition in the B-asset), we can rewrite $D_{A}^{L}\left(\tilde{\theta}, \tilde{p}_{A}, \tilde{p}_{B}\right)$ in terms of $\tilde{p}_{A}$, and the noise in the B-asset market $\tilde{n}_{B}$ as follows:

$$
D_{A}^{L}\left(\tilde{\theta}, \tilde{p}_{A}, \tilde{p}_{B}\right)=\frac{\tilde{\theta}-\tilde{p}_{A}}{\gamma \sigma_{\varepsilon A}^{2}}-\frac{\rho\left(\bar{x}_{B}-\tilde{n}_{B}\right) \sigma_{\varepsilon B}}{\lambda \sigma_{\varepsilon A}} .
$$

Thus, Equation B4 becomes:

$$
\begin{gathered}
\frac{(\lambda+\mu)\left(\tilde{\theta}-\tilde{p}_{A}\right)}{\gamma \sigma_{\varepsilon A}^{2}}-\frac{\rho\left(\bar{x}_{B}-\tilde{n}_{B}\right) \sigma_{\varepsilon B}}{\sigma_{\varepsilon A}}+\tilde{n}_{A}=\bar{x}_{A} \Rightarrow \\
\tilde{s}_{p_{A}} \equiv \tilde{\theta}+\frac{\gamma \sigma_{\varepsilon A}^{2}}{\lambda+\mu}\left(\tilde{n}_{A}+\frac{\rho \sigma_{\varepsilon B}}{\sigma_{\varepsilon A}} \tilde{n}_{B}\right)=\bar{x}_{A}+\frac{\rho \sigma_{\varepsilon B} \bar{x}_{B}}{\sigma_{\varepsilon A}}+\frac{(\lambda+\mu) \tilde{p}_{A}}{\gamma \sigma_{\varepsilon A}^{2}},
\end{gathered}
$$

which is an observable signal to the uninformed S-traders.

Thus, the overall informativeness is then given by:

$$
I_{\text {No-PriceObs }}=\frac{V A R(\tilde{\theta})}{V A R\left(\tilde{\theta} \mid \tilde{p}_{A}\right)}-1=\left(\frac{\lambda+\mu}{\gamma \sigma_{\varepsilon A}^{2}}\right)^{2} \frac{\sigma_{\theta}^{2}}{V A R\left(\tilde{n}_{A}+\frac{\rho \sigma_{\varepsilon B}}{\sigma_{\varepsilon A}} \tilde{n}_{B}\right)} .
$$

It is clear that this is increasing in $\lambda$ and in $\mu$, so an increase in the mass of informed (either L- or $\mathrm{S}$-) traders is always beneficial to informativeness, and there is no strategic complementarity, just like in the traditional Grossman-Stiglitz framework.

To understand the intuition behind this result, consider the hedging component of L-traders' demand in the A-asset market: $-\frac{\rho\left(\phi \tilde{\theta}-\tilde{p}_{B}\right)}{\gamma\left(1-\rho^{2}\right) \sigma_{\varepsilon A} \sigma_{\varepsilon B}}$. Our results in the main text, according to which price informativeness is sometimes decreasing in $\lambda$ and in $\mu$, were driven by the fact that this hedging component is decreasing in $\tilde{\theta}$, and so speculative trading and hedging-motivated trading respond to $\tilde{\theta}$ in opposite directions in the A-asset market, leading to confusion for uninformed S-traders. However, if $\tilde{p}_{B}$ is unknown to the uninformed S-traders, the hedging activity of L-traders in the A-asset market does not reveal strong information about $\tilde{\theta}$ to the uninformed S-traders: in equilibrium, $\tilde{p}_{B}$ changes with $\tilde{\theta}$, and so the hedging component $-\frac{\rho\left(\phi \tilde{\theta}-\tilde{p}_{B}\right)}{\gamma\left(1-\rho^{2}\right) \sigma_{\varepsilon A} \sigma_{\varepsilon B}}$ does not react negatively to $\tilde{\theta}$. As a result, in this case, price informativeness is not harmed by the fact that speculation and hedging provide different trading motives. 


\section{References}

Admati, A. R. 1985. A noisy rational expectations equilibrium for multi-asset securities markets. Econometrica 53:629-58

Adrian, T., and H. S. Shin. 2010. Liquidity and leverage. Journal of Financial Intermediation 19:418-37.

Agarwal, V., W. Jiang, Y. Tang, and B. Yang. 2013. Uncovering hedge fund skill from the portfolio holdings they hide. Journal of Finance 68:739-83.

Almazan, A., K. C. Brown, M. Carlson, and D. A. Chapman. 2004. Why constrain your mutual fund manager? Journal of Financial Economics 73:289-321.

Barberis, N., and A. Shleifer. 2003. Style investing. Journal of Financial Economics 68:161-99.

Barlevy, G., and P. Veronesi. 2000. Information acquisition in financial markets. Review of Economic Studies 67:79-90.

Barlevy, G., and P. Veronesi. 2008. Information acquisition in financial markets: A correction. Review of Economic Studies, Erratum Corrigendum. Available at http://faculty.chicagobooth.edu/pietro.veronesi/research/ BarlevyVeronesi_Correction.pdf.

Bessembinder, H. 1992. Systematic risk, hedging pressure, and risk premiums in futures markets. Review of Financial Studies 5:637-67.

Biais, B., and P. Hillion. 1994. Insider and liquidity trading in stock and options markets. Review of Financial Studies 7:743-80.

Biais, B., P. Bossaerts, and C. Spatt. 2010. Equilibrium asset pricing and portfolio choice under asymmetric information. Review of Financial Studies 23:1503-43.

Boehmer, E., S. Chava, and H. E. Tookes. 2012. Equity market quality: Do cds, options and bond markets play a role? Working Paper, EDHEC Business School, Georgia Institute of Technology, and Yale University.

Breon-Drish, B. M. 2011. Asymmetric information in financial markets: Anything goes. Working Paper, Stanford University

Cespa, G., and T. Foucault. 2012. Illiquidity contagion and liquidity crashes. Working Paper, CSEF and HEC

Chakravarty, S., H. Gulen, and S. Mayhew. 2004. Informed trading in stock and option markets. Journal of Finance 59:1235-57.

Chen, H., J. Miao, and N. Wang. 2010. Entrepreneurial finance and nondiversifiable risk. Review of Financial Studies 23:4348-88.

Choi, D., M. Getmansky, and H. Tookes. 2009. Convertible bond arbitrage, liquidity externalities, and stock prices. Journal of Financial Economics 91:227-51.

Chowhdry, B., and V. Nanda. 1991. Multimarket trading and market liquidity. Review of Financial Studies $4: 483-511$.

Das, S., N. Kalimipalli, and S. Nayak. 2011. Did cds trading improve the market for corporate bonds? Working Paper, Santa Clara University and Wilfrid Laurier University.

Dow, J., and R. Rahi. 2003. Informed trading, investment, and welfare. Journal of Business 76:439-54.

Duffie, D., and R. Rahi. 1995. Financial market innovation and security design: An introduction. Journal of Economic Theory 65:1-42.

Duffie, D. 2010. Presidential address: Asset price dynamics with slow-moving capital. Journal of Finance 65:1237-67.

Easley, D., and M. O'Hara. 2004. Information and the cost of capital. Journal of Finance 59:1553-83.

Eichengreen, B., D. Mathieson, B. Chadha, A. Jansen, L. Kodres, and S. Sharma. 1998. Hedge fund and financial market dynamics. International Monetary Fund, Washington, DC. 
Etula, E. 2010. Broker-dealer risk appetite and commodity returns. Federal Reserve Bank of New York Staff Reports.

Froot, K. A., D. S. Scharfstein, and J. C. Stein. 1992. Herd on the street: Informational inefficiencies in a market with short-term speculation. Journal of Finance 47:1461-84.

Fung, W., and D. A. Hsieh. 1998. Performance attribution and style analysis: From mutual funds to hedge funds. Working Paper, Duke University.

Fung, W., and D. A. Hsieh. 2000. Measuring the market impact of hedge funds. Journal of Empirical Finance 7:1-36.

Garcia, D., and G. Strobl. 2011. Relative wealth concerns and complementarities in information acquisition. Review of Financial Studies 24:169-207.

Glosten, L. R. 1989. Insider trading, liquidity, and the role of the monopolist specialist. Journal of Business 62:211-35.

Goldstein, I., and A. Guembel. 2008. Manipulation and the allocational role of prices. Review of Economic Studies 75:133-64.

Gorton, G. B., F. Hayashi, and K. G. Rouwenhorst. 2013. The fundamentals of commodity futures returns. Review of Finance 17:35-105.

Grossman, S. J., and J. E. Stiglitz. 1980. On the impossibility of informationally efficient markets. American Economic Review 70:393-408.

Hirshleifer, D., A. Subrahmanyam, and S. Titman. 1994. Security analysis and trading patterns when some investors receive information before others. Journal of Finance 49:1665-98.

Hirshleifer, D. 1988a. Residual risk, trading costs, and commodity futures risk premia. Review of Financial Studies 1:173-93.

Hirshleifer, D. 1988b. Risk, futures pricing, and the organization of production in commodity markets. Journal of Political Economy 96:1206-20.

Huang, J., and J. Wang. 2010. Market liquidity, asset prices, and welfare. Journal of Financial Economics 95:107-27.

Karolyi, A., and R. Stulz. 2003. Are Financial Assets Priced Locally or Globally? In The Handbook of the Economics and Finance. Ed. G. Constantinides, M. Harris, and R. M. Stulz. North-Holland, NY: Elsevier.

Keynes, J. M. 1930. A Treatise on Money. Vol. 2 (London: Macmillan).

Koski, J. L., and J. Pontiff. 1999. How are derivatives used? evidence from the mutual fund industry. Journal of Finance 54:791-816.

Kyle, A. S. 1985. Continuous auctions and insider trading. Econometrica 53:1315-35.

Kyle, A. S., H. Ou-Yang, and B. Wei. 2011. A model of portfolio delegation and strategic trading. Review of Financial Studies 24:3778-812.

Lewis, K. K. 1999. Trying to explain home bias in equities and consumption. Journal of Economic Literature 37:571-608.

Li, H., W. Zhang, and G. H. Kim. 2011. The cds-bond basis arbitrage and the cross section of corporate bond returns. Working Paper, University of Michigan and National University of Singapore.

Lo, A. W., H. Mamaysky, and J. Wang. 2004. Asset prices and trading volume under fixed transactions costs. Journal of Political Economy 112:1054-90.

Madhavan, A. 1995. Consolidation, fragmentation, and the disclosure of trading information. Review of Financial Studies 8:579-603.

Mayhew, S. 2000. The impact of derivatives on cash markets: What have we learned? Working Paper, University of Georgia. 
Mele, A., and F. Sangiorgi. 2011. Uncertainty, information acquisition and price swings in asset markets. Working Paper, London School of Economics and Stockholm School of Economics.

Singleton, K. J. Forthcoming. Investor flows and the 2008 boom/bust in oil prices. Management Science.

Sockin, M., and W. Xiong. 2013. Feedback effects of commodity futures prices. Working Paper, Princeton University.

Spiegel, M., and A. Subrahmanyam. 1992. Informed speculation and hedging in a noncompetitive securities market. Review of Financial Studies 5:307-29.

Stein, J. C. 1987. Informational externalities and welfare-reducing speculation. Journal of Political Economy 95:1123-45.

Stulz, R. M. 2007. Hedge funds: Past, present, and future. Journal of Economic Perspectives 21:175-94.

Van Nieuwerburgh, S., and L. Veldkamp. 2009. Information immobility and the home bias puzzle. Journal of Finance 64:1187-215.

Van Nieuwerburgh, S., and L. Veldkamp. 2010. Information acquisition and under-diversification. Review of Economic Studies 77:779-805.

Veldkamp, L. L. 2006a. Information markets and the comovement of asset prices. Review of Economic Studies 73:823-45.

Veldkamp, L. L. 2006b. Media frenzies in markets for financial information. American Economic Review 96:577-601.

Watanabe, M. 2008. Price volatility and investor behavior in an overlapping generations model with information asymmetry. Journal of Finance 63:229-72.

Yuan, K. 2005. Asymmetric price movements and borrowing constraints: A rational expectations equilibrium model of crises, contagion, and confusion. Journal of Finance 60:379-411. 